\title{
TREM2 is required for microglial instruction of astrocytic synaptic engulfment in
}

\section{neurodevelopment}

Taylor R. Jay ${ }^{1}$, Victoria E. von Saucken ${ }^{1,2}$, Braulio Muñoz ${ }^{2,3}$, Juan F. Codocedo ${ }^{2}$, Brady K. Atwood ${ }^{2,3,4}$, Bruce T. Lamb ${ }^{2}$ \& Gary E. Landreth ${ }^{1,2}$

${ }^{1}$ Department of Neurosciences, Case Western Reserve University, 44106

${ }^{2}$ Stark Neurosciences Research Institute, Indiana University School of Medicine, 46202

${ }^{3}$ Department of Psychiatry, Indiana University School of Medicine, 46202

${ }^{4}$ Department of Pharmacology and Toxicology, Indiana University School of Medicine, 46202

Corresponding author information:

Dr. Gary E. Landreth

Stark Neurosciences Research Institute

Indiana University School of Medicine

$320 \mathrm{~W} 15^{\text {th }} \mathrm{St}$

Indianapolis, IN 46202

Phone Number: (317) 278-7820

E-mail: glandret@iu.edu

Running Title: TREM2 in developmental microglial functions

Acknowledgements: This work was supported by the Alzheimer's Association (BFG-15-364590 to GEL), NIA grant RF1 AG051495 (BTL and GEL), NIA grant R01 AG050597 (to GEL), and NIA National Research Service Award F31 AG048704 (to TRJ), NIAAA grant R00 AA023507 (to BKA), and NIH shared instrumentation grant S10-OD024981.

Conflicts of Interest: None

Data Availability Statement: The data that support the findings of this study are available from the corresponding author upon request.

Word Count: 9,281

Main Points:

- TREM2 is required for establishing appropriate microglial size, territory and tiling

- Microglia broadly shape appropriate synapse elimination during neurodevelopment

- Microglia limit synaptic uptake by astrocytes in development through a TREM2-dependent mechanism

This is the author's manuscript of the article published in final edited form as: 


\section{ABSTRACT}

Variants in the microglial receptor TREM2 confer risk for multiple neurodegenerative diseases. However, it remains unknown how this receptor functions on microglia to modulate these diverse neuropathologies. In order to understand the role of TREM2 on microglia more generally, we investigated changes in microglial function in Trem $2^{-\%}$ mice. We found that loss of TREM2 impairs normal neurodevelopment, resulting in reduced synapse number across the cortex and hippocampus in 1-

month-old mice. This reduction in synapse number was not due directly to alterations in interactions between microglia and synapses. Rather, TREM2 was required for microglia to limit synaptic engulfment by astrocytes during development. While these changes were largely normalized later in adulthood, high fat diet administration was sufficient to reinitiate TREM2-dependent modulation of synapse loss. Together, this identifies a novel role for microglia in instructing synaptic pruning by astrocytes to broadly regulate appropriate synaptic refinement, and suggests novel candidate mechanisms for how TREM2 and microglia could influence synaptic loss in brain injury and disease.

Keywords: microglia, astrocyte, glia, pruning 


\section{INTRODUCTION}

Our understanding of microglial function in health (Kierdorf \& Prinz, 2017) and disease (Hickman et al., 2018) has greatly advanced in recent years. Microglia have long been implicated in the pathology of neurodegenerative diseases (NDDs) (Kreutzberg, 1996). However, human genetic studies have only recently provided definitive evidence that microglial dysfunction can actively modulate NDD pathogenesis and progression (Efthymiou \& Goate, 2017; Karch \& Goate, 2015; Ransohoff, 2016), with the identification of TREM2 variants associated with high risk for developing Alzheimer's disease (AD) (Guerreiro et al., 2013; Jonsson et al., 2013). Because the TREM2 receptor is exclusively expressed on microglia in the brain (Jay, von Saucken, \& Landreth, 2017), association of TREM2 variants with AD demonstrates that microglia can play an active role in modulating AD pathology. Since the identification of these variants, a multitude of studies have attempted to elucidate TREM2's role in AD in order to gain insight into key microglial functions in disease. These studies have largely focused on the role of TREM 2 in mediating microglial responses to amyloid plaques, identifying that TREM2 can bind to $A \beta$ peptides (Lessard et al., 2018; Zhao et al., 2018; Zhong et al., 2018) and is required for microglia to accumulate around amyloid plaques (Jay et al., 2015; Ulrich et al., 2014; Wang et al., 2015; Yuan et al., 2016), phagocytose A $\beta$ (Jay et al., 2017; Jiang et al., 2014; Kleinberger et al., 2014; Melchior et al., 2010; Parhizkar et al., 2019; Wang et al., 2016; Yuan et al., 2016) and engage in A $\beta$-driven phenotypic changes in mouse models of $A D$ (Jay et al., 2015; KerenShaul et al., 2017; Wang et al., 2015). While these may represent important functions of TREM2 in AD, TREM2 variants have now also been associated with risk for developing frontotemporal dementia and Parkinson's disease (Jay, von Saucken, \& Landreth, 2017), and are the genetic cause of Nasu Hakola disease (also termed polycystic lipomembranous osteodysplasia with sclerosing leukoencephalopathy, PLOSL) (Paloneva et al., 2002), a progressive neurodegenerative disease characterized by white matter loss, psychosis and dementia (Hakola, 1972; Nasu, Tsukahara, \& Terayama, 1973). The neuropathological features of these diseases are quite diverse, demonstrating that TREM2's essential role in 
neurodegeneration cannot simply be to coordinate amyloid recognition or responses. Indeed, Trem2 was found to be part of a genetic signature that defines a subset of microglia present in many NDD contexts (Krasemann et al., 2017). Thus, it is likely that TREM2 serves a broader role on microglia, regulating functions of these cells that converge on common features of brain injury and disease.

Recently, the similarities between microglial roles in neurodegeneration and normal brain development have begun to be appreciated. Complement proteins, for example, were previously known to mediate microglial elimination of supernumerary synapses which are produced during initial stages of brain development (Schafer et al., 2012; Stevens et al., 2007). Complement has also been implicated in microglial elimination of synapses in $A D$, mediating pathological loss of synapses in AD mouse models (Hong et al., 2016; Shi et al., 2017). Complement is also involved in synaptic loss in response to acute brain injury (Alawieh et al., 2018; Norris et al., 2018), chronic tau accumulation (Dejanovic et al., 2018), epilepsy (Wyatt et al., 2017), neuroinflammation (Watkins et al., 2016) and other disease contexts (Sekar et al., 2016). Other microglial signaling components also have important functions in both brain development and neurodegeneration, including CX3CR1 (Basilico et al., 2019; Paolicelli et al., 2011; Sheridan \& Murphy, 2013) and progranulin (Baker et al., 2006; Lui et al., 2016), further illustrating that common mechanisms can mediate important microglial functions in brain health and disease (Tenner, Stevens, \& Woodruff, 2018).

Evidence already indicates that TREM2 may also have roles in microglial regulation of normal brain development. Patients with the TREM2-related genetic disorder PLOSL begin to exhibit neurological symptoms in their 20's (Kaneko et al., 2010). This age of onset coincides with a late adolescent period of developmental synaptic pruning (Keshavan, Anderson, \& Pettegrew, 1994), suggesting the possibility that TREM2 could normally play a role in regulating that process. In support of this, recent work has identified changes in brain circuitry of TREM2 deficient mice at P20, a time point which similarly follows a period of 
heightened synaptic refinement (Filipello et al., 2018). Even studies of individuals who carry TREM2 variants associated with NDDs with typical onset in late adulthood have found changes in brain volume (Luis et al., 2014) and cognitive function (Jonsson et al., 2013; Montalbetti et al., 2005) even decades before these individuals exhibit clinical manifestations of disease. These data argue that microglial-driven changes in brain function that occur far earlier in development can influence later NDD pathogenesis.

If TREM2 does have functional roles in the healthy brain, it could provide a genetic starting point to expand our understanding of normal microglial functions, as it has already provided important insights into roles of microglia in disease. We do not know how broadly microglia are involved in the essential function of synaptic elimination in nervous system development, whether they interact with other cell populations to mediate appropriate synaptic refinement, or the extent of diversity in the mechanisms that these cells use to engage in circuit remodeling at different times and in different circuits.

We assessed the function of TREM2 in neurodevelopment to identify novel roles for microglia in the healthy brain. We found that microglia are critical for shaping neurodevelopement quite broadly, with distinct roles in different cortical and hippocampal regions. Perturbing TREM2 function in microglia led to enhanced synaptic uptake by astrocytes. Together, this study identifies a broad requirement for microglia in appropriately establishing and modifying synapses, finds a novel, TREM2-dependent mechanism for these changes, and establishes that microglia instruct other glial populations to appropriately shape synaptic connections in development and adulthood.

\section{METHODS}

\section{Mice}

Trem2 ${ }^{-1}$ mice (TREM2tm1(KOMP)Vlcg) express a lacZ reporter in place of exons 2, 3 and part of 4 and were 
previously validated to lack TREM2 expression (Jay et al., 2015). Littermate controls of both sexes, all maintained on a B6/SJL background, were used in all experiments. Electrophysiology experiments were performed on mice housed at the Stark Neurosciences Research Institute at Indiana University and procedures were approved by the IU School of Medicine IACUC committee. Mice used for all other experiments were housed in the animal facility at Case Western Reserve University and approved by the Case Western Reserve University IACUC committee. All mice had ad libitum access to food and water. Where indicated, mice received a high fat diet (Harlan-Tekland 7960) from 1-4 months of age.

\section{Synaptosome isolation}

Synaptosomes were isolated (Dunkley, Jarvie, \& Robinson, 2008) and prepared as previously described (Chung et al., 2013). Briefly, mice were anesthetized with isoflurane, decapitated and their brains removed and homogenized in $3 \mathrm{~mL}$ gradient buffer ( $320 \mathrm{mM}$ sucrose, $1.2 \mathrm{mM}$ EDTA, $5 \mathrm{mM}$ Tris, $\mathrm{pH} 7.4$ ) for $1.25 \mathrm{~min}$ using a mechanical homogenizer. This solution was centrifuged in $12 \mathrm{~mL}$ polycarbonate tubes in a $\mathrm{J} 20$ rotor at $3,600 \mathrm{rpm}$ for $10 \mathrm{~min}$ at $4^{\circ} \mathrm{C}$. The supernatant (S1 fraction) was divided and reserved for Western blot analysis and the remainder diluted to $4-5 \mathrm{mg} / \mathrm{mL}$ protein. $2 \mathrm{~mL}$ of this fraction was layered over a 3\% / 10\% / 15\% / 23\% discontinuous percoll (GE Healthcare 17089101) gradient prepared in gradient buffer and centrifuged at $20,000 \mathrm{rpm}$ for $5 \mathrm{~min}$ at $4^{\circ} \mathrm{C}$ with the lowest deceleration setting. Fraction 4 at the interface of $3 \%$ and $10 \%$ gradients and fraction 3 taken at the interface of $10 \%$ and $15 \%$ gradients were collected, diluted in gradient buffer and centrifuged at $16,000 \mathrm{rpm}$ for $20 \mathrm{~min}$ at $4^{\circ} \mathrm{C}$. The pellet was washed and resuspended in $0.1 \mathrm{M}$ sodium carbonate $\mathrm{pH} 9.0$ at a concentration of $5 \mathrm{mg} / \mathrm{mL}$. An aliquot from each sample was reserved for Western blot analysis, and the remainder labeled with 137nM concentration of pHrodo Red succinimidyl ester (Thermo Fischer P36600) by shaking at room temperature for $2 \mathrm{hr}$ at $120 \mathrm{rpm}$. Conjugated synaptosomes were washed in PBS, resuspended in PBS with 5\% DMSO 
and frozen slowly in a Styrofoam container at $-20^{\circ} \mathrm{C}$. Before use, synaptosomes were rapidly thawed at $37^{\circ} \mathrm{C}$, counted on a hemocytometer, and diluted to a final concentration of 10,000 synaptosomes $/ \mathrm{mL}$ in serum free DMEM/F12 media.

\section{Protein isolation and western blots}

To obtain cortical and hippocampal lysates, mice were perfused with PBS, cortices and hippocampi dissected and snap frozen on dry ice. Brains were homogenized in PBS with 1\% NP-40, $0.5 \%$ sodium deoxycholate and $0.1 \%$ SDS, sonicated and centrifuged. Protein from synaptosomal fractions was prepared as described above. Protein concentration was determined using a BCA kit (Thermo Scientific). Proteins were boiled for $5 \mathrm{~min}$ at $95^{\circ} \mathrm{C}$ in sample buffer containing DTT. $25 \mu \mathrm{g}$ of protein per sample for cortical and hippocampal lysates and $2 \mu \mathrm{g}$ of protein for synaptosome enriched fractions were loaded into $4-12 \%$ Bis-Tris gels (Life Technologies) and run at $100 \mathrm{~V}$ in MOPS running buffer. Protein was transferred onto IR-compatible PVDF membranes on ice in a Tris glycine buffer containing methanol at 100V for $1 \mathrm{hr}$. Membranes were blocked in TBS Odyssey Blocking Buffer diluted 1:1 with TBS for 1 hour at room temperature and incubated with the indicated primary antibodies in blocking buffer overnight at $4^{\circ} \mathrm{C}$ : Actin (Santa Cruz sc-1615, 1:5000), C1q (Abcam ab182451), Gas6 (R\&D AF986, 1:10000), GAPDH (Santa Cruz sc-32233, 1:10000), HDAC1 (Abcam ab19845, 1:1000), Histone H3 (Abcam ab1791, 1:2500), $\mathrm{Na}+\mathrm{K}+\mathrm{ATPase}$ (Abcam ab76020, 1:5000), NR2A (Millipore 07-632, 1:2000), NR2B (Millipore 06-600, 1:2000), Protein S (R\&D MAB4976, 1:350), PSD95 (Invitrogen MA1-046, 1:2000), Synapsin (Abcam ab64581, 1:1000), or Synaptophysin (Abcam ab16659, 1:5000). Membranes were washed in TBS and incubated in a 1:10,000 dilution of the appropriate IR dye conjugated secondary antibody in blocking buffer for 1 hour at room temperature. Membranes were imaged and analyzed using the Odyssey imaging system. Each sample was normalized to actin or GAPDH as indicated and the graphs represent 
these values normalized to the mean of the Trem $2+/+$ group.

\section{ELISAs}

Protein was isolated as previously described and concentration determined using a BCA kit (Thermo Scientific). Each sample was diluted to a final concentration of $2 \mathrm{mg} / \mathrm{mL}$. Assays were otherwise performed using the reagents and instructions provided in the Quantikine ELISA Mouse M-CSF (R\&D MMCO0) and Quantikine ELISA Mouse IL-34 (R\&D M3400) kits. Plates were imaged using a BioTek Synergy HTX plate reader and analyzed as instructed.

\section{RNA isolation and qPCR}

Homogenized brain lysates were prepared as described above and added to an equal volume of RNA-Bee before storing at $-80^{\circ} \mathrm{C}$ until use. RNA was isolated using chloroform extraction and purified using the Purelink RNA Mini Kit (Life Technologies). Samples were treated with an on-column DNAse Purelink kit (Life Technologies). cDNA was prepared from 250ng - 1 $\mu$ g of RNA using a QuantiTech Reverse Transcription kit (Qiagen) and qPCR performed using the StepOne Plus Real Time PCR system (Life Technologies) with Taqman assays. Relative gene expression was assessed relative to GAPDH or cell-type specific controls as indicated. Data are graphed as fold change gene expression and $\Delta C_{T}$ values were used for statistical comparisons.

\section{Slice preparation and immunohistochemistry}

Mice were perfused with PBS, brains removed and one hemisphere drop fixed in $4 \%$ PFA at $4^{\circ} \mathrm{C}$ overnight 
and cryoprotected in 30\% sucrose before snap freezing in OCT. Brains were cryosectioned into $30 \mu \mathrm{m}$ free floating sections and were stored in cryoprotectant buffer at $-20^{\circ} \mathrm{C}$ until use. Slices were permeabilized in PBS with $0.1 \%$ Triton- $X$ and antigen retrieval was performed using $10 \mathrm{mM}$ sodium citrate with $0.5 \%$ Tween $\mathrm{pH} 6.0$ at $85^{\circ} \mathrm{C}$ for $15 \mathrm{~min}$ and then at room temperature for $30 \mathrm{~min}$. Slices were blocked $(5 \%$ Normal Donkey Serum, $0.3 \%$ TritonX-100 in PBS pH7.4) for $1 \mathrm{hr}$ and then incubated in the following primary antibodies overnight at $4^{\circ} \mathrm{C}$ : Aldhl1 (Abcam ab87117, 1:250), GFAP (Abcam ab7260, 1:1000), Iba1 (Wako 019-19741, 1:500), PSD95 (Millipore MAB1596, 1:100 - 1:200) or synaptophysin (Cell Signaling 5461, 1:1000). Slices were incubated with Alexa-fluor conjugated secondary antibodies at a 1:1000 concentration for $1 \mathrm{hr}$ at room temperature, stained with a 1:10000 concentration of DAPI in PBS, washed and mounted using Prolong Gold.

\section{Image Acquisition and Analysis}

\section{Synapse Number}

Immunohistochemistry for synaptophysin and PSD95 was performed as described above on 3 medial sections per animal. Confocal images were acquired at $63 x$ and optical slices were acquired at the center of each slice spanning $0.5 \mu \mathrm{m}$ of tissue. Maximum projections were obtained from these $z$ stacks, correcting for photobleaching by normalizing the signal to the average signal of each slice. Images were thresholded based on secondary only controls run with each experiment. For analyses at 1 month of age, the number of each synaptic element was quantified using General Analysis on NIS AR Software (Nikon) and apposed synaptic elements determined by using the "min distance" function with a distance $0.5 \mu \mathrm{m}$. For analyses at 4 months of age, the number of synaptic elements and apposed synaptic elements within $0.5 \mu \mathrm{m}$ was determined using the puncta analyzer plugin for ImageJ (Ippolito \& Eroglu, 2010). For each animal, at least 3 images were analyzed per slice for each region and results were averaged to generate 
each replicate used in the analysis.

\section{Microglial density and territory}

Immunohistochemistry was performed for Iba1 on 1 medial and 1 lateral sagittal brain section for each animal and images were acquired on a Hamamatsu Nanozoomer S60 slide scanner. DAPI was used to define brain regions of interest and Iba1+ cells were manually counted within each region in ImageJ. The number of cells was normalized to the area of each region counted to yield the reported microglial number / area. The cell bodies identified were also analyzed using the Delaunay/Voronoi plugin for ImageJ. The results of the Voronoi tessellations were thresholded and the area of each cell determined. Those located on the edges were excluded from the analysis. The average area defined by the tessellations are reported as mean territory. The variation of the territories was analyzed in GraphPad Prism in which column analyses were used to determine the coefficient of variance of the territories defined for each region for each animal. These are reported as territory variance.

\section{Microglial morphology}

Sholl analyses on microglia were performed as previously described with minor modifications (Norris, Derecki, \& Kipnis, 2014). Briefly, 3 medial sections per animal were stained for Iba1 and 63x confocal images were acquired with optical slices set at $1 \mathrm{AU}$ across the $30 \mu \mathrm{m}$ sections. Images were thresholded and maximum projections were prepared from z stacks. Any extraneous signal was manually erased. Because cell body size was found to be different between Trem $2^{+/+}$and Trem $2^{-/}$microglia (data not shown), the Sholl analysis protocol was modified such that the experimenter defined the longest distance across the cell body and the first radius of the Sholl analysis was set to start $1 \mu \mathrm{m}$ away from that distance. 
Subsequent radii were defined $5 \mu \mathrm{m}$ apart as previously described and the results reported as calculated by the Sholl analysis plugin for ImageJ.

The hull and circle algorithm was also used to assess microglial morphology. The hull and circle plugin for ImageJ defines the smallest convex hull which contains the entirety of each microglia's processes, and further defines a circle that circumscribes that convex hull. The measures are reported as calculated by the hull and circle plugin. Cellular replicates were used across all analyses of microglial morphology.

\section{Engulfment of PSD95 in microglia and astrocytes}

Iba1 and PSD95 immunohistochemistry was performed on 1 medial and 1 lateral slice per animal. Z stacks were acquired at $63 \mathrm{x}$ with $1 \mathrm{AU} \mathrm{z}$ steps through the $30 \mu \mathrm{m}$ tissue. Individual microglia were isolated from each image and cells thresholded. PSD95 was thresholded based on secondary only controls run with each experiment and the PSD95 within the thresholded area of each cell was quantified. Volume was calculated by multiplying the area within each image by the $z$ step value. Results are reported as the PSD95 volume within Iba1+ microglia divided by cell volume, multiplied by 100 .

A similar procedure was used to quantify synaptic material in astrocytes from slices stained with Aldhl1 and PSD95. However, because of the extent of astrocyte processes, it was not possible to isolate individual astrocytes and so a similar analysis was performed as described above but across each $63 x$ field.

For analyses that compared PSD95 uptake by microglia and astrocytes, volume of astrocytes was reported from the analysis described above. For microglia, the analysis above was repeated using the same protocol used for astrocytes, quantifying volume of glia and PSD95 volume within a given imaging field rather than for individual cells. Cellular replicates were used for statistical analyses of PSD95 
engulfment.

\section{Electrophysiology}

1-1.5-month-old mice were anesthetized using isoflurane and sacrificed by rapid decapitation. The brain was removed, placed in an ice-cold cutting solution (194mM sucrose, $30 \mathrm{mM} \mathrm{NaCl}, 4.5 \mathrm{mM} \mathrm{KCl}, 1 \mathrm{mM} \mathrm{MgCl}$, $26 \mathrm{mM} \mathrm{NaHCO}_{3}, 1.2 \mathrm{mM} \mathrm{NaH}_{2} \mathrm{PO}_{4}, 10 \mathrm{mM}$ glucose) saturated with $95 \% \mathrm{O}_{2}$ and $5 \% \mathrm{CO}_{2}$, and $280 \mu \mathrm{m}$ slices were prepared using a vibratome (Leica VT1200S). Slices were transferred to artificial cerebral spinal fluid (aCSF: $124 \mathrm{mM} \mathrm{NaCl}, 4.5 \mathrm{mM} \mathrm{KCl}, 1 \mathrm{mM} \mathrm{MgCl}_{2}, 26 \mathrm{mM} \mathrm{NaHCO}_{3}, 1.2 \mathrm{mM} \mathrm{NaH}_{2} \mathrm{PO}_{4}, 10 \mathrm{mM}$ glucose, $2 \mathrm{mM} \mathrm{CaCl}_{2}$ ) saturated with $95 \% \mathrm{O}_{2}$ and $5 \% \mathrm{CO}_{2}$ at $30^{\circ} \mathrm{C}$ for 1 hour and then kept at room temperature until recording. For recording, brain slices were transferred to a chamber that was continuously perfused with aCSF containing $0.5 \mu \mathrm{M} T \mathrm{TX}$ and $50 \mu \mathrm{M}$ picrotoxin at a rate of $1-2 \mathrm{~mL} / \mathrm{min}$ in $5 \% \mathrm{CO}_{2}$ at $29-32^{\circ} \mathrm{C}$ and visualized using an Olympus BX51WI microscope (Olympus Corporation of America). Whole cell voltage clamp recordings were performed using a Multiclamp 700B amplifier (Molecular Devices). Hippocampal CA1 neurons were patch clamped using filament-containing borosilicate micropipettes (World Precision Instruments) using a P1000 micropipette puller (Sutter Instruments) with a 2-4 $\mathrm{M} \Omega$ resistance filled with $120 \mathrm{mM} \mathrm{CsMeSO}, 5 \mathrm{mM}$ $\mathrm{NaCl}, 10 \mathrm{mM}$ TEA-Cl, 10mM HEPES, 5mM lidocaine bromide, 1.1mM EGTA, 0.3mM Na-GTP and 4mM MgATP, pH 7.2. Voltage was held at $-60 \mathrm{mV}$ and miniature excitatory postsynaptic currents (mEPSCs) were acquired across a 3min time window using pClamp 10.3 software (Molecular Devices). Only cells with a series resistance less than $25 \mathrm{M} \Omega$ that did not change more than $15 \%$ during recording were included for data analysis. mEPSCs analysis was performed using MiniAnalysis 6.0 (Synaptosoft Inc). Recordings from slices prepared from Trem2 $^{+/+}$and Trem2 ${ }^{-/}$littermates were acquired in the same recording session in randomized order and the experimenter was blinded to genotype. Each $\mathrm{n}$ represents a cell, which were recorded from 3 animals of each genotype. 


\section{In vitro preparation of microglia and astrocytes}

P2 Trem2 $^{+/+}$and Trem2 ${ }^{-/}$littermates were sacrificed by decapitation, brains were removed and washed in PBS with glucose. Brains were dissociated in $0.05 \%$ Trypsin in EDTA for $20 \mathrm{~min}$ at $37^{\circ} \mathrm{C}$. Brains were transferred into DMEM/F12 media with $10 \%$ FBS and triturated until homogenous. Cells were plated and left 2-3 weeks at $37^{\circ} \mathrm{C}$ with $5 \% \mathrm{CO}_{2}$. Astrocytes were removed from the plate with a $1: 3$ dilution of $0.25 \%$ Trypsin in HBSS in DMEM/F12 media. Plates were washed and microglia removed with $0.25 \%$ Trypsin in PBS. Cells were spun down and resuspended in DMEM/F12 with 10\% FBS. Microglia for conditioned media collection were plated at a density of 1,000,000 cells / well in 6 well plates. After 24 hours, cells were washed and switched to serum free media. Media was collected and replaced every 48 hours for 4 days. Cells used for imaging were plated at 300,000 cells / well in ibiTreated 8-well chamber slides (ibidi 80826).

\section{Live cell imaging}

After 24 hours, cells were labeled with a 1:1000 concentration of CellTracker (Thermo Fischer C2110) in media for $30 \mathrm{~min}$ at $37^{\circ} \mathrm{C}$. Cells were washed and media was replaced. All cells received fresh, serum free media except for astrocytes which were treated with microglia conditioned media. After 6 hours, pHrodo conjugated synaptosomes, prepared as described above, were added to the media. Cells were imaged at $37^{\circ} \mathrm{C}$ at $5 \%$ humidity over the course of 16 hours. Six $20 x$ images were acquired across each well at each time point. Cells were imaged again at 24 hours and either fixed in 4\% PFA for $5 \mathrm{~min}$ and stored in PBS, or washed and media replaced for 16 hours before fixation. 


\section{Immunocytochemistry and Imaging}

After fixation, cells were washed in PBS and blocked (3\% Normal Donkey Serum, $0.2 \%$ Triton-X, 0.5\% BSA in PBS pH7.4) for $1 \mathrm{hr}$ at room temperature. Cells were incubated in block with PSD95 (Millipore MAB1596, $1: 1000)$ at $4^{\circ} \mathrm{C}$ overnight. Cells were washed and incubated in a 1:1000 concentration of Alexa-conjugated secondary antibody in block for $1 \mathrm{hr}$ at room temperature. Cells were washed and kept in PBS for imaging. One hundred 20x tiled images were acquired for each well.

\section{Cell Imaging Analysis}

For analysis of synaptic uptake in fixed cells, images of each well were stitched together and a threshold determined to assess the total area of cells across each well. pHrodo+ signal that localized within cells was thresholded and the area quantified. This area was divided by the total cell area. Within each experiment, each replicate was normalized to the $\mathrm{Trem}^{+/+}$average and reported as percent internalized synaptosome volume normalized to Trem2 $2^{+/+}$. For experiments assessing uptake of Trem $^{+/+}$vs Trem $2^{-/}$synaptosomes, replicates were defined as individual mice from which synaptosomes were isolated. For experiments assessing uptake of synaptosomes by $\operatorname{Trem}^{+/+}$vs $\mathrm{Trem}^{-/-}$microglia, replicates were defined as individual pups from which microglia were cultured.

For analysis of degradation of synaptic material, two wells for each replicate were included on each plate. One well was fixed after $24 \mathrm{hr}$ exposure to synaptosomes (condition A) and the other transferred to fresh media and fixed after an additional $16 \mathrm{hr}$ (condition B). As described above, images were stitched and the total cell area thresholded. pHrodo+ area within regions defined as cells was identified and the percent of that area that was also PSD95+ quantified. The ratio of this value in condition B to condition A was determined for each replicate. Any values greater than 1 were excluded from the 
analysis. This ratio was then subtracted from 1 and multiplied by 100 to yield the reported value of percent degraded PSD95.

For live cell imaging experiments, the cell threshold was determined across the imaged regions and the pHrodo+ area within cells quantified as described above. Within each experiment, each replicate at each time point was normalized to the average percent internalized synaptosome volume quantified in unconditioned media conditions after 24 hours of incubation. In these experiments, each replicate represents an individual mouse from which microglia were cultured and conditioned media was collected.

\section{Statistics}

Statistical analyses were performed using GraphPad Prism. mEPSC frequency and amplitude were analyzed using a two-sample Kolmogorov-Smirnov test. Two-sided, unpaired t-tests were used to determine statistical differences in all other cases where two groups were compared. 2-way ANOVAs with Tukey posthoc tests were used in contexts in which multiple variables were being simultaneously compared. Column statistics were performed to identify outliers and these samples were excluded. Except as specifically defined for electrophysiological experiments, live cell imaging and analysis of microglial morphology and synaptic uptake, each $\mathrm{n}$ represents a biological replicate. In box and whisker plots, the box represents the $25^{\text {th }}-75^{\text {th }}$ interquartile range and whiskers represent the min and $\max$ values. Bar graphs represent the mean and error bars denote the SEM. Mice from three separate cohorts were included for each group.

\section{RESULTS}

\section{TREM2 deficient mice exhibit changes in synaptic connections following development}


To determine whether TREM2 has a biologically meaningful role in shaping brain development, we assessed whether Trem2 $\%$ mice exhibited alterations in synaptic transmission at 1-1.5-months of age, a time point just after most developmental synapse formation and elimination is normally complete (Thion \& Garel, 2017). Whole cell voltage clamp recordings of CA1 neurons in hippocampal slices prepared from Trem $^{+/+}$and Trem2 $^{-/-}$mice (Fig 1A) revealed a significant and substantial reduction in mEPSC frequency with loss of TREM2 (Fig 1B). This supports a TREM2-dependent role for microglia in regulating appropriate synaptic connections in the hippocampus.

Microglia have recently been shown to be required for postsynaptic maturation of CA1 neurons through a CX3CR1-dependent mechanism (Basilico et al., 2019). To determine whether there were also TREM2-dependent changes in postsynaptic function in this region, we evaluated mEPSC amplitude (Fig 1C), mEPSC rise and decay time and AMPA:NMDA ratios, but found no significant effect of Trem2 genotype on these measures of postsynaptic function (data not shown). Thus, TREM2 and CX3CR1 have separable roles in mediating microglia-dependent development in this region. Rather than synaptic maturation, the selective decrease in mEPSC frequency observed in Trem $2^{-/}$mice suggests that there are either fewer synapses onto CA1 neurons or that presynaptic function of these inputs is impaired.

\section{TREM2 expression is broadly required for appropriate regulation of synapse number}

To assess whether the electrophysiological changes observed in TREM2 deficient mice were due to changes in synapse number, we quantified the number of synaptophysin+ pre-synaptic elements, PSD95+ excitatory postsynaptic elements, and their apposition (Fig 1D), which have previously been used to evaluate microglial modulation of synapse number in other contexts (Ippolito \& Eroglu, 2010). TREM2 deficiency resulted in a significant decrease in the number of presynaptic elements and a strong trend toward a reduction in apposed synaptic elements (Fig $1 \mathrm{E}$ ) in CA1, suggesting that a reduction in 
synapse number is likely responsible for the TREM2-dependent electrophysiological changes observed.

While microglia have previously been shown to affect synapses in CA1 (Filipello et al., 2018;

Paolicelli et al., 2011), we wanted to assess whether TREM2 was also required for establishing appropriate synapse number more broadly across the brain. To evaluate this, we quantified synapses across several regions of the cortex and hippocampus (Fig 1F). We found that there were significant reductions in synaptophysin+ presynaptic elements almost globally across the regions analyzed, and we observed a significant reduction in apposed synaptic elements in many of these regions (Table 1). In the motor cortex, we also found reductions in postsynaptic elements (Fig 1G). These data demonstrate that there are widespread effects of TREM2 deficiency on synaptic development.

While quantification of synaptophysin and PSD95+ puncta has previously been used to evaluate synapse number, it is possible that the changes observed in these measurements could instead represent alterations in the composition of synapses themselves. To ensure that our data did not reflect a change in abundance or localization of these specific proteins at the synapse, we prepared enriched synaptosomal fractions from brains of Trem2 $2^{+/+}$and Trem2 ${ }^{-/}$mice (Fig S1A). In Western blots on lysates prepared from these fractions (Fig $1 \mathrm{H}$ ), we observed no differences in the levels of synaptophysin (Fig 1I) or PSD95 (Fig 1J), indicating that the abundance of these proteins at synapses was unaffected. To ensure that our results were not specific to these markers, we also evaluated levels of additional synaptic components within synaptosome enriched fractions (Fig S1B) and detected no differences in other presynaptic elements, including synapsin (Fig S1C) or postsynaptic elements, including NR2B (Fig S1D) and NR2A (Fig S1E). While these synaptosomes were isolated from the whole brain, and therefore we cannot exclude the possibility of region-specific differences in synaptic protein distribution, these data are suggestive of a requirement for TREM 2 in regulation of brain development by controlling appropriate synapse number. 


\section{TREM2 deficiency increases the amount of synaptic material engulfed by each microglial cell}

There could be several possibilities for how microglia regulate synapse number. Microglia are known to alter both production and elimination of neurons during development (Freeman, 2006), but we detected no differences in neuronal number across any brain region examined (data not shown). Microglia can also control synapse number by directly engaging in engulfment of supernumerary synapses (Schafer et al., 2012). To evaluate whether TREM2 expression affected engulfment of synaptic material in microglia, we quantified the volume of PSD95+ elements internalized within $\mathrm{Trem}^{+/+}$and Trem2 $\%$ microglia (Fig 2A). TREM2 deficient microglia contained significantly more engulfed PSD95 in layer $\mathrm{V}$ of the motor cortex (Fig 2B), where we had previously observed decreases in postsynaptic elements. In CA1 (Fig 2C) and other brain regions where postsynaptic elements were unaffected by Trem2 genotype, we observed no significant differences in PSD95 engulfment (Table 2), demonstrating a correlation between increased synaptic engulfment by microglia and reduced synapse number.

The increased presence of synaptic material within Trem2 ${ }^{-/}$microglia could be due to intrinsic differences in the ability of TREM2 deficient microglia to engulf synapses. To evaluate this possibility, we cultured primary microglia from Trem $2^{+/+}$or Trem $2^{-/}$littermates and exposed these cells to pHrodo conjugated synaptosomes isolated from the brains of $\mathrm{Trem}^{+/+}$mice (Fig S2A). After incubating cells with synaptosomes for 24 hours, cells were fixed and the volume of engulfed synaptosomes quantified and normalized to total cell volume. We observed no differences in synaptosome uptake between Trem2 $2^{+/+}$ and Trem2\% microglia (Fig S2B). In this system, degradation of engulfed synaptic material was also unaffected by Trem2 genotype (Fig S2C).

Since we did not detect any intrinsic differences in the ability of $\mathrm{Trem}^{+/+}$and $\mathrm{Trem}^{2-}$ microglia to engulf or degrade synaptic elements in vitro, we evaluated whether the increased synaptic engulfment 
by Trem $_{2} \%$ microglia in vivo might instead be due to differences in the properties of synapses present in the brains of Trem2 ${ }^{-1}$ mice. To determine whether these synapses might be a better substrate for microglial engulfment, we evaluated whether Trem2 ${ }^{-}$mice had increased levels of complement components, which are known to serve as tags to target microglial synapse elimination (Stevens et al., 2007). There were no significant changes in gene expression of complement components in the cortex (Fig S2D) or hippocampus (data not shown), though there was a trend toward an increase in C1q protein expression in cortical lysates (Fig S2E). We were unable to detect C1q or C3 in synaptosome enriched protein fractions to determine whether there were also genotype-dependent alterations in association of complement proteins with synapses. Cultured microglia showed no preference for uptake of synaptosomes isolated from the brains of Trem2 ${ }^{-/}$mice relative to Trem2 $2^{+/+}$controls (Fig S2E). Thus, we were unable to identify any differences in the intrinsic capacity of microglia to engulf more synapses, nor were synapses from Trem $^{-/}$mice clearly a better substrate for microglial engulfment in the assays performed.

\section{TREM2 is required to establish appropriate microglial number and regulates microglial distribution}

While the intrinsic capacity of Trem2 ${ }^{\%}$ microglia to engulf synapses was not significantly altered, perhaps there were other changes in the phenotype of $\mathrm{Trem}^{-/-}$microglia that could influence synaptic uptake in vivo. Upon examining microglia in the brains of TREM2 deficient mice, striking differences in microglial morphology were apparent (Fig 3A). We analyzed microglial size and structure using Sholl analysis (Fig 3B) as previously described (Norris et al., 2014) and used a hull and circle algorithm to assess features of the size and distribution of the territory occupied by each cell (Fig 3B). Sholl analysis revealed an increase in the total number of intersecting branches across concentric radii established around the cell body (Fig 3C). This was not due to changes in the extent of branching of these cells, as the number of primary 
branches extending from the cell body (Fig 3D) and the mean number of branches intersecting each concentric radius (Fig 3E) were unchanged. Rather, increased total branch number was driven by an increase in the size of $\mathrm{Trem}^{2} \%$ microglia as measured by the distance from the center of the cell body to the edge of the longest process (Fig 3F). We further assessed whether there were changes in the distribution or polarity of the branches, but found no differences in the circularity of the convex hull circumscribing the microglial processes (Fig 3G), the ratio of the minimum and maximum radii drawn through the convex hull (Fig $3 \mathrm{H}$ ), or the ratio of the area of the convex hull to the bounding circle (Fig 3I) with Trem2 genotype. However, the average area of the convex hull was significantly increased in Trem2'- microglia (Fig 3J), further supporting an increase in cell size and consequently the area occupied by each cell. Similar results were observed across many brain regions (Table 3). This demonstrates that TREM2 is dispensable for determining the appropriate morphological features of microglia, but is required for determining the appropriate size of these cells.

We wanted to determine whether differences in the properties of individual microglia observed in Trem2 ${ }^{-/}$mice would also affect the distribution of these cells across the brain. To address this, we identified cell bodies of microglia across several brain regions and used these as seeds to generate Voronnoi tessellations, which define territories in which each point is closer to the cell body of a given microglia than it is to any other microglial cell body (Fig 3K). Using this method, we found that the average territory occupied by each microglia was significantly larger in Trem2 ${ }^{-/}$mice across the cortex, hippocampus (Fig $3 \mathrm{~L}$ ) and other brain regions (Fig S3A). This method of analysis has also previously been used to assess the regularity of microglial distribution (Bouvier et al., 2016). Interestingly, we found that in addition to occupying larger territories, Trem2\% microglia had more variability in territory size (Fig 3M, S3B). This suggests that TREM2 is not only required for determining microglial size, but also to ensure regular tiling of these cells. How microglial tiling is controlled, up to now, is unknown, but our data clearly implicate TREM2 in this process. 
Because TREM2 deficient microglia occupy larger territories, unless these territories overlap and violate normal principles of microglial tiling, there must be fewer microglia in the brains of Trem $^{-\%}$ mice. Indeed, when we quantified the number of microglia (Fig S3C) across the cortex, hippocampus (Fig 3N), and other brain regions (Fig S3D), there was a significant effect of genotype by 2-way ANOVA, reflective of a nearly universal reduction in the density of microglia. One exception was in the posterior parietal cortex, in which we also failed to observe changes in microglial size (Table 3) or significant differences in territory mean (Fig $3 \mathrm{~L}$ ) or variance (Fig $3 \mathrm{M}$ ), suggesting that these features may be coordinately regulated. TREM2 has previously been shown to interact with CSF1R signaling (Wang et al., 2015), and signaling through the CSF1 receptor on microglia is required for their survival (Elmore et al., 2014). We tested whether changes in CSF1R signaling could be responsible for the reduction in microglial number observed in Trem2 ${ }^{-/}$mice. While gene expression of CSF1R and its ligands CSF1 and IL34 (Wang et al., 2012) were unchanged in cortical and hippocampal lysates (data not shown), we did detect a trend toward a decrease in CSF1 (Fig S3E) and a significant decrease in IL34 (Fig S3F) protein levels by ELISA in cortical lysates from Trem2 ${ }^{-/}$mice. This indicates that TREM2 does interact with the CSF1R signaling pathway, which likely contributes to the reduction in microglia number in Trem2 ${ }^{-/}$mice, and may also drive changes in microglial size and distribution.

\section{Uptake of synaptic elements by microglia as a population is reduced in Trem2-/- mice}

As we previously showed, individual microglia engulf more synapses in TREM2 deficient mice across several brain regions (Fig 30). However, our data also show that TREM2 deficiency reduces the number of total microglia in these areas. To investigate whether microglia as a population contain more synapses, we normalized the number of engulfed PSD95+ synaptic elements within microglia to the differences in microglial density between genotypes. The ratio of PSD95+ elements in microglia in Trem2- 
1- mice relative to $\mathrm{Trem}^{+/+}$mice was significantly below 1 for almost all regions examined (Fig 3P), indicating that overall synaptic engulfment by microglia is reduced. This also suggests that individual microglia may take up more synapses in Trem2 ${ }^{-/}$mice simply because there are more synapses available for engulfment.

\section{TREM2 is required to limit synaptic uptake by astrocytes}

Based on the finding that $\mathrm{Trem}^{-\%}$ microglia as a population engulf fewer synapses, we would expect that synaptic number would be increased in Trem $2 \%$ mice. But we clearly showed that synaptic numbers are reduced, to the point of having substantial effects on electrophysiology in Trem2 ${ }^{-/}$mice. If this isn't mediated by enhanced engulfment of synapses by microglia, then microglia must regulate synapse number through another mechanism. It has recently been shown that in contexts of injury or neurodegeneration, microglia potently influence the phenotype of astrocytes (Liddelow et al., 2017). Like microglia, astrocytes also engage in synaptic engulfment during development (Chung, Allen, \& Eroglu, 2015). However, it has never been evaluated whether microglia can influence developmental synapse elimination by astrocytes.

To address whether TREM2 could influence synapse number by mediating microglial influence over astrocytic synaptic pruning, we tested whether astrocytes in Trem2 ${ }^{-/}$mice engulfed more synapses by assessing the volume of PSD95 internalized within Aldhl1+ astrocytes in the brains of Trem2 $2^{+/+}$and Trem $^{-/}$mice (Fig 4A). Indeed, we found that there was an increase in internalized synaptic elements within astrocytes in Trem2 $\%$ mice in layer V of the motor cortex (Fig 4B), CA1 (Fig 4C) and many other brain regions (Table 4). There was no change in astrocyte volume across these regions (Fig S4C). Together, this demonstrates that TREM2 deficiency does increase synaptic engulfment by astrocytes and establishes a novel role for microglia in instructing astrocyte synapse engulfment during brain 
development. In support of a role for microglia in modulation of astrocytic synaptic uptake, we found that in vitro, microglia conditioned media could significantly inhibit synaptosome uptake by astrocytes (Fig S4A, B). Conditioned media from Trem2\% also inhibited uptake of synaptosomes by astrocytes, except at 24 hours, when there was no significant difference between synaptic uptake by astrocytes exposed to unconditioned media or Trem $2^{-/}$conditioned media. This may indicate that $T r e m 2^{-/}$microglia fail to produce some of the factors produced by microglia that normally serve to limit synaptic uptake by astrocytes. However, only brain regions in which microglial number was significantly reduced by TREM2 deficiency showed increased synaptic engulfment by astrocytes (Table 4), suggesting that a decrease in the population of microglia is likely a primary contributor to enhanced astrocytic engulfment in Trem2 $\%$ mice.

\section{Increased engulfment of synapses in astrocytes in TREM2 deficient mice contributes to a reduction in} synapse number

The increase in synapse engulfment within astrocytes could explain the reduction in synapse number observed in TREM2 deficient mice. However, because synaptic uptake is reduced in Trem $2^{- \text {microglia, to }}$ fully explain the synaptic loss, astrocytes in Trem $2^{-/}$mice must increase synaptic uptake by more than Trem2 $^{-/}$microglia reduce it. To determine whether microglia or astrocytes engulfed more synapses, we first compared the percent volume of each glial subtype that was comprised of internalized PSD95. In layer $\mathrm{V}$ of the motor cortex, per volume, microglia contain more synaptic material than astrocytes (Fig 4D). However, astrocytes occupy substantially more volume within the brain (Fig 4E). Thus, when the total internalized PSD95+ volume within glia is quantified, the decrease in synaptic uptake by microglia is far outweighed by the increase in synaptic engulfment by astrocytes (Fig 4F). While we have not fully excluded other possible contributions to the decrease in synapse number, such as alterations in synapse 
formation (Fig S4D) (Ullian et al., 2001), enhanced engulfment of synaptic elements by glia clearly contributes to the synaptic reductions observed in TREM2 deficient mice. In contrast to our expectation that these differences would be driven directly through TREM2's effect on interactions between microglia and synapses, these changes are instead driven by an impaired ability of microglia to appropriately limit astrocytic synaptic engulfment.

\section{Many TREM2-dependent developmental changes observed at 1 month of age are normalized later in adulthood}

To investigate whether the changes we observed at 1 month of age persist throughout the lifetime of the animal, we quantified synapse number in 4-month-old Trem $2^{+/+}$and $T r e m 2^{--}$mice (Fig 5A). At this age, there were no longer significant differences in synaptic elements in layer $\mathrm{V}$ of the motor cortex (Fig 5B) or in CA1 (Fig 5C). Microglial engulfment of PSD95 at 4 months of age (Fig 5D) was reduced in layer V of the motor cortex in TREM2 deficient mice (Fig 5E, Table 5) with no change in CA1 (Fig 5F). The changes we observed previously in microglial size, as measured by the area of the convex hull (Fig 5G) and the length of the longest process (Fig $5 \mathrm{H}$ ) were also normalized. There were also no significant differences with Trem2 genotype in microglial territory size (Fig 5I) or variance (Fig 5J). Correspondingly, the density of microglia was no longer significantly altered at this age (Fig 5K). Because we posited that at 1 month of age, reductions in microglial number may have been due to reduced CSF1R signaling, we investigated whether expression of CSF1R and its ligands were also normalized by 4 months of age. Similar to what we observed at 1 month, there was no genotype-dependent difference in CSF1R gene expression (data not shown), and there was still a significant reduction in protein levels of the ligand IL34 in Trem ${ }^{-/}$mice (Fig S5A). CSF1 protein levels did normalize at this age (Fig S5A), but it remains to be determined whether this is responsible for the recovery in microglial density or whether other cues may also 
mediate microglial survival and abundance later in adulthood.

In 1-month-old Trem2\% mice, enhanced synaptic uptake by astrocytes accounted for the increase in synaptic loss we observed, so we wanted to determine whether this was similarly normalized by 4 months of age. Consistent with the return to normal synapse number, uptake of PSD95 in astrocytes (Fig $5 \mathrm{~L}$ ) was no longer significantly altered in Trem2 ${ }^{--}$mice compared to $\mathrm{Trem}^{+/+}$mice in motor CX layer V (Fig 5M, Table 7) or CA1 (Fig 5N, Table 7). However, unlike at 1 month of age, there was a significant decrease in several genes associated with astrocyte-driven synapse formation and maturation in cortical lysates from 4-month-old TREM2 deficient mice (Fig S5B), suggesting that there may still be microglialdriven changes in how astrocytes influence new synapse formation or synaptic function later in adulthood.

\section{Developmental TREM2-dependent synaptic reductions can be reinitiated in adulthood}

By 4 months of age, many aspects of microglial and astrocytic phenotypes that were altered with TREM 2 deficiency earlier in development were apparently normalized and synapse number was no longer significantly altered, suggesting that there are likely additional mechanisms that control synaptic uptake by astrocytes later in adulthood that are independent of TREM2. However, glial developmental functions have been shown to be aberrantly reinitiated in adulthood (Hong et al., 2016) in response to injury, infection or metabolic challenge. To test whether the developmental function of TREM2 in regulating appropriate synapse number could be reinitiated in adulthood in these contexts, we administered a high fat diet. Trem $2^{+/+}$and $T r e m 2^{-/}$mice were fed a standard diet until they reached 1 month of age, at which time littermates were separated and either maintained on a standard diet or fed a high fat diet until they were sacrificed at 4 months. We then evaluated whether there was an interaction between TREM2 deficiency and high fat diet in the number of synaptic elements present in different brain regions. In 
layer $\mathrm{V}$ of the motor cortex, there was no significant interaction between genotype and diet in the number of synaptophysin+ (Fig 6A) or PSD95+ (Fig 6B) elements alone. But, we did find that diet had a significant effect only in Trem2 $\%$ mice on measures of apposed synaptic elements (Fig 6C), which reflect the total possible number of functional synapses (Ippolito \& Eroglu, 2010), and in the proportion of synaptophysin+ elements which were apposed to PSD95 (Fig 6D) as well as the proportion of PSD95+ elements that were apposed to synaptophysin (Fig 6E). Similar effects were also observed in other brain regions, including layers II and III of the motor cortex (Fig 6F-J) and CA1 (Fig 6K-O). Together, the reduction in synapses in Trem2 ${ }^{-/}$mice with high fat diet administration suggests that TREM2 is required on microglia to regulate appropriate synapse number in later adulthood following metabolic challenge, as was observed during development. In this context, however, TREM2 also seems to be required to modulate the specificity of synapse elimination, as in some regions such as layer $\mathrm{V}$ of the motor cortex, there were no changes in individual synaptic elements, but those remaining in $\mathrm{Trem}_{2}{ }^{-}$mice were less likely to be engaged in synaptic contacts. This demonstrates that TREM2 can play a role in regulation of synapse number in adulthood following high fat diet administration and may also be required in this context for selective maintenance of functional synapses.

\section{DISCUSSION}

\section{Synaptic changes in TREM2 deficient mice}

In this study, we demonstrate that TREM2 is critical for appropriate synaptic refinement during neurodevelopment. Microglia have previously been implicated in this process in the lateral geniculate nucleus (Schafer et al., 2012) and the CA1 region of the hippocampus (Filipello et al., 2018; Paolicelli et al., 2011). Our study extends these findings by demonstrating that microglia affect development very broadly across the nervous system, as TREM2 deficiency led to changes in synapse number in several 
regions of the cortex and hippocampus. We report a robust reduction in mEPSC frequency in CA1 neurons in Trem2 $\%$ mice at 1-1.5 month of age, due to a reduction in synapse number. This finding is distinct from that reported by Filipello and colleagues, who reported increased mEPSC frequency in P18P20 mice with TREM2 deficiency, consistent with an increase in synaptic protein levels (Filipello et al., 2018). The basis for these discordant outcomes is unclear. The differences between our studies could be due to dynamic changes in how TREM2 regulates microglial-dependent synapse elimination over the course of development, but in control experiments (not shown) we also found reductions in mEPSC frequency in CA1 neurons at P20, consistent with what we observed at 1-1.5 months of age. Another possibility is a difference in the Trem $2^{-/}$model we used. Our model has recently been shown to display an increase in another gene within the Trem locus, Treml1 (Kang et al., 2018), while Filipello and colleagues' knockout models do not (Filipello et al., 2018). However, we also confirmed our electrophysiology results in mice with a knock-in of the Trem2 R47H variant which exhibits substantial loss of Trem2 gene expression in mice due to the introduction of a cryptic splice site (Xiang et al., 2018), but does not alter expression of Treml1 or other genes in the Trem locus (Cheng-Hathaway et al., 2018). Again, we observed a decrease in mEPSCs in these knock-in mice (data not shown), demonstrating that the differences aren't model specific. Because we found that the TREM2-dependent synaptic loss in our model could be modulated by diet, it is possible that our opposing findings are due to differences in as of yet undefined environmental factors.

TREM2 deficiency affected the number of synapses and glial engulfment of synaptic elements across several brain regions. However, we found that while synaptophysin was reduced across most regions, PSD95 was specifically affected in the motor cortex. This suggests that microglia have different roles in directing targeting of particular synaptic elements depending on the circuit. The regional differences we observed in synaptic changes in Trem2 ${ }^{-/}$mice could be due to regional diversity of microglia (Grabert et al., 2016). Perhaps the TREM2-dependent microglial signals that modulate synapse 
elimination are differentially expressed or astrocytes in different brain regions may be differentially responsive to these cues. These factors may also change over time, governing when different circuits undergo heightened periods of synaptic refinement.

The normalization of appropriate synapse number by 4 months of age in TREM2 deficient mice suggests that there are additional mechanisms which normally serve to limit inappropriate elimination of synapses by glia later in adulthood. However, we found that TREM2 can again influence synapse number in 4-month-old mice following high fat diet administration. While high fat diet administraiton was used simply as a means of altering the brain inflammatory environment in this study, these findings do indicate an important interaction between TREM2 and diet on CNS function and it would be of interest to determine whether TREM2 could be related to metabolic syndrome in future studies. It is not yet clear whether this is driven by reinitiation of the same mechanisms by which TREM2 influences developmental synaptic refinement. However, TREM2 is also known to affect the phenotype of astrocytes in AD mouse models (Jay et al., 2017; Jay et al., 2015). It will be of great interest to determine whether influencing the phenotype of astrocytes is a common function of TREM2 across metabolic challenge, injury and disease states, and whether these changes result in astrocyte-driven synaptic alterations in these other contexts. If so, regulation of astrocytic synaptic engulfment may be a key mechanism for how TREM2 broadly influences NDD pathology.

\section{Microglia instruct synaptic elimination by astrocytes}

One of the key findings of this study is that microglia interact with astrocytes to coordinate their shared function of synaptic refinement during development. There are examples of microglia influencing the phenotype of astrocytes in disease or injury (Liddelow et al., 2017), and our study extends these findings by identifying a role for communication between these cell types in normal brain function. 
Specifically, we found that microglia can limit astrocyte uptake of synapses. This effect was partially dependent on TREM2 expression, resulting in increased astrocytic engulfment of synaptic elements in 1month-old Trem2 ${ }^{-/}$mice. The signals that mediate this effect seem to be released from microglia, as microglia conditioned media was able to effectively limit astrocytic synaptic uptake. It is not entirely clear what these signals might be. Through release of TNFa, IL1 and C1q, microglia have previously been shown to reduce astrocytic gene expression of the receptors MerTK and Megf10 (Liddelow et al., 2017), which are required for their engulfment of synapses during neurodevelopment (Chung et al., 2015). Thus, release of these factors by microglia could be responsible for decreasing astrocytic synaptic engulfment. Other possible candidates for microglial-derived signals include TGF $\beta$, which is known to reduce astrocytosis (Liddelow et al., 2017) and has also been shown to limit synapse loss following astrocyte activation (Diniz et al., 2017). Microglial derived FGF has been shown to be important for limiting astrocyte activation (Kang et al., 2014) though its specific effect on synaptic uptake by astrocytes has not yet been evaluated. In addition to the release of soluble factors, microglia have also been shown to communicate with other brain cell types through release of extracellular vesicles (Delpech et al., 2019; Paolicelli et al., 2019), which could also mediate microglial signaling to astrocytes in this context. Identifying the signals used by microglia to alter astrocyte synaptic uptake promises to provide a means to potently regulate astrocytic elimination of synapses which would be of great interest in pathological contexts in which aberrant glial function drives synaptic loss.

\section{Changes in microglial phenotype in TREM2 deficient mice}

In Trem2 ${ }^{-\%}$ mice, microglia contained more engulfed synaptic elements in several brain regions. Because TREM2 has been shown to be required for phagocytosis of a variety of substrates, including apoptotic cells (Hsieh et al., 2009; Yeh et al., 2016) this could have been due to intrinsic differences in the ability of 
Trem $^{-/}$microglia to take up or degrade synapses. However, Trem $2^{+/+}$and Trem $2^{-/}$microglia displayed no differences in synaptic uptake or degradation in vitro, though because microglia undergo extensive transcriptional changes when removed from the brain microenvironment (Bohlen et al., 2017), we cannot exclude that in vivo these cells have a different capacity for synaptic uptake or degradation. Alternatively, we thought that synapses themselves may be different in Trem2 ${ }^{-1}$ mice in some way that made them a better substrate for engulfment. We did not detect a preference for uptake of Trem2 ${ }^{-/}$ synaptosomes by microglia, nor did we detect genotype-dependent changes in expression of complement components. However, it is possible that there are changes in protective signals such as SIRP $\alpha$ which has recently been shown to inhibit microglial uptake of synapses (Lehrman et al., 2018) or yet to be identified alternative cues that direct microglial synapse elimination. However, in our study, we posit that the major contributor to an increase in synaptic elements within microglia is simply because these cells are larger and cover a larger territory, thus having more possible synapses available for uptake.

These TREM2-dependent changes in microglial size and distribution are important because very little is known about what normally governs these fundamental processes during microglial development and homeostasis. It is well known that the number of microglia in the brain is tightly regulated (Askew et al., 2017; Fuger et al., 2017), in part though CSF1R signaling. CSF1R antagonists effectively eliminate microglia from the brain (Elmore et al., 2014) and zebrafish and patients with CSF1R mutations display reduced microglial density (Oosterhof et al., 2018). TREM2 deficiency did result in reduced levels of the CSF1R ligand IL34, which may be responsible for the reduction in microglial number in $\mathrm{Trem}^{-\%}$ mice. It remains to be understood how TREM2 influences IL34 protein levels, as it is thought to be produced exclusively by neurons. Because TREM2 is known to be important for microglial proliferation (Otero et al., 2012; Zheng et al., 2017) and chemotaxis (Mazaheri et al., 2017) in response to damage or disease, it may also be that a failure in these processes contributes to the reduction in microglia observed in brain 
development.

TREM2 is also important for establishing appropriate microglial size and tiling. In Trem2\% mice, microglial structure was unchanged, but the cells were larger. This demonstrates that microglial size and structure are governed by separable mechanisms. In addition to regulating the size of the territories that microglia occupy, TREM2 was also required for establishing the regularity of microglial territories. This regularity of tiling is integral for microglia to be able to efficiently sample the brain microenvironment, and the identification that this requires TREM2 provides the first insight into pathways that govern this process.

\section{Implications for TREM2 function in neurodegenerative diseases}

Microglial number, size and distribution are also features that change dramatically and rapidly following injury or disease. Just as TREM2 was required to establish the appropriate number of microglia during development, it has also been shown to be required for expansion of the microglial population following brain injury (Kawabori et al., 2015; Poliani et al., 2015; Saber et al., 2017; Sieber et al., 2013) and for changes in microglial distribution in AD mouse models (Jay et al., 2015; Ulrich et al., 2014; Wang et al., 2015; Yuan et al., 2016). This suggests that TREM2 may work through a common mechanism to establish microglial number and distribution in the healthy brain and appropriately recalibrate these features in disease. Future studies will be required to determine whether TREM2 is also required to protect against disease-associated synaptic loss through similar mechanisms to those identified here.

Studying the functional role of TREM2 on microglia provided novel insights into critical functions of these cells in the normal brain. We found that microglia play a widespread role in neurodevelopment, and showed that they can limit synaptic uptake by astrocytes, thus tuning the appropriate level of developmental synapse elimination. Microglia continue to integrate a wide variety of environmental cues, including diet and disease-related factors and communicate these conditions to astrocytes in such 
a way that meaningfully changes their phenotype and regional synapse number in adulthood.

Uncovering these important functions of microglia in brain homeostasis also suggest novel roles for microglia which could importantly modulate brain injury and disease. 


\section{REFERENCES}

Alawieh, A., Langley, E. F., Weber, S., Adkins, D., \& Tomlinson, S. (2018). Identifying the role of complement in triggering neuroinflammation after traumatic brain injury. J Neurosci. doi:10.1523/jneurosci.2197-17.2018

Askew, K., Li, K., Olmos-Alonso, A., Garcia-Moreno, F., Liang, Y., Richardson, P., . . Gomez-Nicola, D. (2017). Coupled Proliferation and Apoptosis Maintain the Rapid Turnover of Microglia in the Adult Brain. Cell Rep, 18(2), 391-405. doi:10.1016/j.celrep.2016.12.041

Baker, M., Mackenzie, I. R., Pickering-Brown, S. M., Gass, J., Rademakers, R., Lindholm, C., ... Hutton, M. (2006). Mutations in progranulin cause tau-negative frontotemporal dementia linked to chromosome 17. Nature, 442(7105), 916-919. doi:10.1038/nature05016

Basilico, B., Pagani, F., Grimaldi, A., Cortese, B., Di Angelantonio, S., Weinhard, L., . . Ragozzino, D. (2019). Microglia shape presynaptic properties at developing glutamatergic synapses. Glia, 67(1), 53-67. doi:10.1002/glia.23508

Bohlen, C. J., Bennett, F. C., Tucker, A. F., Collins, H. Y., Mulinyawe, S. B., \& Barres, B. A. (2017). Diverse Requirements for Microglial Survival, Specification, and Function Revealed by Defined-Medium Cultures. Neuron, 94(4), 759-773.e758. doi:10.1016/j.neuron.2017.04.043

Bouvier, D. S., Jones, E. V., Quesseveur, G., Davoli, M. A., T, A. F., Quirion, R., . . Murai, K. K. (2016). High Resolution Dissection of Reactive Glial Nets in Alzheimer's Disease. Sci Rep, 6, 24544. doi:10.1038/srep24544

Cheng-Hathaway, P. J., Reed-Geaghan, E. G., Jay, T. R., Casali, B. T., Bemiller, S. M., Puntambekar, S. S., .. Landreth, G. E. (2018). The Trem2 R47H variant confers loss-of-function-like phenotypes in Alzheimer's disease. 13(1), 29. doi:10.1186/s13024-018-0262-8

Chung, W. S., Allen, N. J., \& Eroglu, C. (2015). Astrocytes Control Synapse Formation, Function, and Elimination. Cold Spring Harb Perspect Biol, 7(9), a020370. doi:10.1101/cshperspect.a020370 
Chung, W. S., Clarke, L. E., Wang, G. X., Stafford, B. K., Sher, A., Chakraborty, C., . . Barres, B. A. (2013). Astrocytes mediate synapse elimination through MEGF10 and MERTK pathways. Nature, 504(7480), 394-400. doi:10.1038/nature12776

Dejanovic, B., Huntley, M. A., De Maziere, A., Meilandt, W. J., Wu, T., Srinivasan, K., .. Sheng, M. (2018). Changes in the Synaptic Proteome in Tauopathy and Rescue of Tau-Induced Synapse Loss by C1q Antibodies. Neuron, 100(6), 1322-1336.e1327. doi:10.1016/j.neuron.2018.10.014

Deplech, J.C., Herron, S., Botros, M.B., \& Ikezu, I. (2019). Neuroimmune Crosstalk through Extracellular Vesciles in Health and Disease. Trends Neurosci 42(5), 361-372. doi: 10.1016/j.tins.2019.02.007 Diniz, L.P., Tortelli, V., Matias, I., Morgado, J, Araujo, A.P.B., Melo, H.M., . . Gomes, F.C.A. (2017). Astrocyte Transforming Growth Factor Beta 1 Protects Synapses against A $\beta$ Oligomers in Alzheimer's Disease Model. J Neurosci, 27(28), 6797-6809. doi: 10.1523/JNEUROSCI.3351-16.2017

Dunkley, P. R., Jarvie, P. E., \& Robinson, P. J. (2008). A rapid Percoll gradient procedure for preparation of synaptosomes. Nat Protoc, 3(11), 1718-1728. doi:10.1038/nprot.2008.171

Efthymiou, A. G., \& Goate, A. M. (2017). Late onset Alzheimer's disease genetics implicates microglial pathways in disease risk. Mol Neurodegener, 12(1), 43. doi:10.1186/s13024-017-0184-x

Elmore, M. R., Najafi, A. R., Koike, M. A., Dagher, N. N., Spangenberg, E. E., Rice, R. A., . . Green, K. N. (2014). Colony-stimulating factor 1 receptor signaling is necessary for microglia viability, unmasking a microglia progenitor cell in the adult brain. Neuron, 82(2), 380-397. doi:10.1016/j.neuron.2014.02.040

Filipello, F., Morini, R., Corradini, I., Zerbi, V., Canzi, A., Michalski, B., ... Matteoli, M. (2018). The Microglial Innate Immune Receptor TREM2 Is Required for Synapse Elimination and Normal Brain Connectivity. Immunity, 48(5), 979-991.e978. doi:10.1016/j.immuni.2018.04.016

Freeman, M. R. (2006). Sculpting the nervous system: glial control of neuronal development. Curr Opin Neurobiol, 16(1), 119-125. doi:10.1016/j.conb.2005.12.004 
Fuger, P., Hefendehl, J. K., Veeraraghavalu, K., Wendeln, A. C., Schlosser, C., Obermuller, U., ... Jucker, M. (2017). Microglia turnover with aging and in an Alzheimer's model via long-term in vivo single-cell imaging. Nat Neurosci, 20(10), 1371-1376. doi:10.1038/nn.4631

Grabert, K., Michoel, T., Karavolos, M. H., Clohisey, S., Baillie, J. K., Stevens, M. P., . . McColl, B. W. (2016). Microglial brain region-dependent diversity and selective regional sensitivities to aging. Nat Neurosci, 19(3), 504-516. doi:10.1038/nn.4222

Guerreiro, R., Wojtas, A., Bras, J., Carrasquillo, M., Rogaeva, E., Majounie, E., . . Hardy, J. (2013). TREM2 variants in Alzheimer's disease. N Engl J Med, 368(2), 117-127. doi:10.1056/NEJMoa1211851

Hakola, H. P. (1972). Neuropsychiatric and genetic aspects of a new hereditary disease characterized by progressive dementia and lipomembranous polycystic osteodysplasia. Acta Psychiatr Scand Suppl, 232, 1-173.

Hickman, S., Izzy, S., Sen, P., Morsett, L., \& El Khoury, J. (2018). Microglia in neurodegeneration. Nature Neuroscience, 21(10), 1359-1369. doi:10.1038/s41593-018-0242-x

Hong, S., Beja-Glasser, V. F., Nfonoyim, B. M., Frouin, A., Li, S., Ramakrishnan, S., . . Stevens, B. (2016). Complement and microglia mediate early synapse loss in Alzheimer mouse models. Science, 352(6286), 712-716. doi:10.1126/science.aad8373

Hsieh, C. L., Koike, M., Spusta, S. C., Niemi, E. C., Yenari, M., Nakamura, M. C., \& Seaman, W. E. (2009). A role for TREM2 ligands in the phagocytosis of apoptotic neuronal cells by microglia. J Neurochem, 109(4), 1144-1156. doi:10.1111/j.1471-4159.2009.06042.x

Ippolito, D. M., \& Eroglu, C. (2010). Quantifying synapses: an immunocytochemistry-based assay to quantify synapse number. J Vis Exp(45). doi:10.3791/2270

Jay, T. R., Hirsch, A. M., Broihier, M. L., Miller, C. M., Neilson, L. E., Ransohoff, R. M., . . Landreth, G. E. (2017). Disease Progression-Dependent Effects of TREM2 Deficiency in a Mouse Model of Alzheimer's Disease. J Neurosci, 37(3), 637-647. doi:10.1523/jneurosci.2110-16.2016 
Jay, T. R., Miller, C. M., Cheng, P. J., Graham, L. C., Bemiller, S., Broihier, M. L., . . Lamb, B. T. (2015). TREM2 deficiency eliminates TREM2+ inflammatory macrophages and ameliorates pathology in Alzheimer's disease mouse models. J Exp Med, 212(3), 287-295. doi:10.1084/jem.20142322

Jay, T. R., von Saucken, V. E., \& Landreth, G. E. (2017). TREM2 in Neurodegenerative Diseases. Mol Neurodegener, 12(1), 56. doi:10.1186/s13024-017-0197-5

Jiang, T., Tan, L., Zhu, X. C., Zhang, Q. Q., Cao, L., Tan, M. S., . . Yu, J. T. (2014). Upregulation of TREM2 ameliorates neuropathology and rescues spatial cognitive impairment in a transgenic mouse model of Alzheimer's disease. Neuropsychopharmacology, 39(13), 2949-2962. doi:10.1038/npp.2014.164

Jonsson, T., Stefansson, H., Steinberg, S., Jonsdottir, I., Jonsson, P. V., Snaedal, J., . . Stefansson, K. (2013). Variant of TREM2 associated with the risk of Alzheimer's disease. N Engl J Med, 368(2), 107-116. doi:10.1056/NEJMoa1211103

Kaneko, M., Sano, K., Nakayama, J., \& Amano, N. (2010). Nasu-Hakola disease: The first case reported by Nasu and review: The 50th Anniversary of Japanese Society of Neuropathology. Neuropathology, 30(5), 463-470. doi:10.1111/j.1440-1789.2010.01127.x

Kang, S. S., Kurti, A., Baker, K. E., Liu, C. C., Colonna, M., Ulrich, J. D., . . Fryer, J. D. (2018). Behavioral and transcriptomic analysis of Trem2-null mice: not all knockout mice are created equal. Hum Mol Genet, 27(2), 211-223. doi:10.1093/hmg/ddx366

Karch, C. M., \& Goate, A. M. (2015). Alzheimer's disease risk genes and mechanisms of disease pathogenesis. Biol Psychiatry, 77(1), 43-51. doi:10.1016/j.biopsych.2014.05.006

Kawabori, M., Kacimi, R., Kauppinen, T., Calosing, C., Kim, J. Y., Hsieh, C. L., . . Yenari, M. A. (2015). Triggering receptor expressed on myeloid cells 2 (TREM2) deficiency attenuates phagocytic activities of microglia and exacerbates ischemic damage in experimental stroke. J Neurosci, 35(8), 3384-3396. doi:10.1523/jneurosci.2620-14.2015 
Keren-Shaul, H., Spinrad, A., Weiner, A., Matcovitch-Natan, O., Dvir-Szternfeld, R., Ulland, T. K., ... Amit, I. (2017). A Unique Microglia Type Associated with Restricting Development of Alzheimer's Disease. Cell, 169(7), 1276-1290.e1217. doi:10.1016/j.cell.2017.05.018

Keshavan, M. S., Anderson, S., \& Pettegrew, J. W. (1994). Is schizophrenia due to excessive synaptic pruning in the prefrontal cortex? The Feinberg hypothesis revisited. J Psychiatr Res, 28(3), 239265.

Kierdorf, K., \& Prinz, M. (2017). Microglia in steady state. The Journal of Clinical Investigation, 127(9), 3201-3209. doi:10.1172/JCI90602

Kleinberger, G., Yamanishi, Y., Suárez-Calvet, M., Czirr, E., Lohmann, E., Cuyvers, E., . . Mazaheri, F. (2014). TREM2 mutations implicated in neurodegeneration impair cell surface transport and phagocytosis. Sci Transl Med, 6(243), 243ra286-243ra286.

Krasemann, S., Madore, C., Cialic, R., Baufeld, C., Calcagno, N., El Fatimy, R., .. Butovsky, O. (2017). The TREM2-APOE Pathway Drives the Transcriptional Phenotype of Dysfunctional Microglia in Neurodegenerative Diseases. Immunity, 47(3), 566-581.e569. doi:10.1016/j.immuni.2017.08.008

Kreutzberg, G. W. (1996). Microglia: A sensor for pathological events in the CNS. Trends in Neurosciences, 19(8), 312-318. doi:10.1016/0166-2236(96)10049-7

Lehrman, E. K., Wilton, D. K., Litvina, E. Y., Welsh, C. A., Chang, S. T., Frouin, A., . . Stevens, B. (2018). CD47 Protects Synapses from Excess Microglia-Mediated Pruning during Development. Neuron, 100(1), 120-134.e126. doi:10.1016/j.neuron.2018.09.017

Lessard, C. B., Malnik, S. L., Zhou, Y., Ladd, T. B., Cruz, P. E., Ran, Y., . . Golde, T. E. (2018). High-affinity interactions and signal transduction between Abeta oligomers and TREM2. EMBO Mol Med, 10(11). doi:10.15252/emmm.201809027

Liddelow, S. A., Guttenplan, K. A., Clarke, L. E., Bennett, F. C., Bohlen, C. J., Schirmer, L., . . Barres, B. A. (2017). Neurotoxic reactive astrocytes are induced by activated microglia. Nature, 541, 481. 
doi:10.1038/nature21029

Lui, H., Zhang, J., Makinson, S. R., Cahill, M. K., Kelley, K. W., Huang, H. Y., . . Huang, E. J. (2016).

Progranulin Deficiency Promotes Circuit-Specific Synaptic Pruning by Microglia via Complement Activation. Cell, 165(4), 921-935. doi:10.1016/j.cell.2016.04.001

Luis, E. O., Ortega-Cubero, S., Lamet, I., Razquin, C., Cruchaga, C., Benitez, B. A., . . Pastor, P. (2014). Frontobasal gray matter loss is associated with the TREM2 p.R47H variant. Neurobiology of Aging, 35(12), 2681-2690. doi:10.1016/j.neurobiolaging.2014.06.007

Mazaheri, F., Snaidero, N., Kleinberger, G., Madore, C., Daria, A., Werner, G., . . Haass, C. (2017). TREM2 deficiency impairs chemotaxis and microglial responses to neuronal injury. EMBO Rep, 18(7), 1186-1198. doi:10.15252/embr.201743922

Melchior, B., Garcia, A. E., Hsiung, B.-K., Lo, K. M., Doose, J. M., Thrash, J. C., . . Carson, M. J. (2010). Dual Induction of TREM2 and Tolerance-Related Transcript, Tmem176b, in Amyloid Transgenic Mice: Implications for Vaccine-Based Therapies for Alzheimer's Disease. ASN Neuro, 2(3), AN20100010. doi:10.1042/AN20100010

Montalbetti, L., Ratti, M. T., Greco, B., Aprile, C., Moglia, A., \& Soragna, D. (2005). Neuropsychological tests and functional nuclear neuroimaging provide evidence of subclinical impairment in NasuHakola disease heterozygotes. Funct Neurol, 20(2), 71-75.

Nasu, T., Tsukahara, Y., \& Terayama, K. (1973). A lipid metabolic disease-"membranous lipodystrophy"-an autopsy case demonstrating numerous peculiar membrane-structures composed of compound lipid in bone and bone marrow and various adipose tissues. Acta Pathol Jpn, 23(3), 539-558.

Norris, G., Derecki, N., \& Kipnis, J. (2014). Microglial Sholl Analysis. doi.org/10.1038/protex.2014.029

Norris, G. T., Smirnov, I., Filiano, A. J., Shadowen, H. M., Cody, K. R., Thompson, J. A., . . Kipnis, J. (2018). Neuronal integrity and complement control synaptic material clearance by microglia after CNS injury. J Exp Med, 215(7), 1789-1801. doi:10.1084/jem.20172244 
Oosterhof, N., Kuil, L. E., van der Linde, H. C., Burm, S. M., Berdowski, W., van ljcken, W. F. J., ... van Ham, T. J. (2018). Colony-Stimulating Factor 1 Receptor (CSF1R) Regulates Microglia Density and Distribution, but Not Microglia Differentiation In Vivo. Cell Rep, 24(5), 1203-1217.e1206. doi:10.1016/j.celrep.2018.06.113

Otero, K., Shinohara, M., Zhao, H., Cella, M., Gilfillan, S., Colucci, A., ... Colonna, M. (2012). TREM2 and beta-catenin regulate bone homeostasis by controlling the rate of osteoclastogenesis. J Immunol, 188(6), 2612-2621. doi:10.4049/jimmunol.1102836

Paloneva, J., Manninen, T., Christman, G., Hovanes, K., Mandelin, J., Adolfsson, R., . . Peltonen, L. (2002). Mutations in two genes encoding different subunits of a receptor signaling complex result in an identical disease phenotype. Am J Hum Genet, 71(3), 656-662. doi:10.1086/342259

Paolicelli, R. C., Bolasco, G., Pagani, F., Maggi, L., Scianni, M., Panzanelli, P., . . Gross, C. T. (2011). Synaptic pruning by microglia is necessary for normal brain development. Science, 333(6048), 1456-1458. doi:10.1126/science.1202529

Paolicelli, R.C., Bergamini, G., \& Rajendran, L. (2019). Cell-to-cell Communication by Extracellular Vesicles: Focus on Microglia. Neuroscience, 405, 148-157. doi: 10.1016/j.neuroscience.2018.04.003

Parhizkar, S., Arzberger, T., Brendel, M., Kleinberger, G., Deussing, M., Focke, C., . . Haass, C. (2019). Loss of TREM2 function increases amyloid seeding but reduces plaque-associated ApoE. Nature Neuroscience. doi:10.1038/s41593-018-0296-9

Poliani, P. L., Wang, Y., Fontana, E., Robinette, M. L., Yamanishi, Y., Gilfillan, S., \& Colonna, M. (2015). TREM2 sustains microglial expansion during aging and response to demyelination. J Clin Invest, 125(5), 2161-2170. doi:10.1172/jci77983

Ransohoff, R. M. (2016). How neuroinflammation contributes to neurodegeneration. Science, 353(6301), 777-783. doi:10.1126/science.aag2590

Saber, M., Kokiko-Cochran, O., Puntambekar, S. S., Lathia, J. D., \& Lamb, B. T. (2017). Triggering Receptor 
Expressed on Myeloid Cells 2 Deficiency Alters Acute Macrophage Distribution and Improves Recovery after Traumatic Brain Injury. J Neurotrauma, 34(2), 423-435. doi:10.1089/neu.2016.4401

Schafer, D. P., Lehrman, E. K., Kautzman, A. G., Koyama, R., Mardinly, A. R., Yamasaki, R., . . Stevens, B. (2012). Microglia sculpt postnatal neural circuits in an activity and complement-dependent manner. Neuron, 74(4), 691-705. doi:10.1016/j.neuron.2012.03.026

Sekar, A., Bialas, A. R., de Rivera, H., Davis, A., Hammond, T. R., Kamitaki, N., . . McCarroll, S. A. (2016). Schizophrenia risk from complex variation of complement component 4. Nature, 530, 177. doi:10.1038/nature16549

Sheridan, G. K., \& Murphy, K. J. (2013). Neuron-glia crosstalk in health and disease: fractalkine and CX3CR1 take centre stage. Open Biol, 3(12), 130181. doi:10.1098/rsob.130181

Shi, Q., Chowdhury, S., Ma, R., Le, K. X., Hong, S., Caldarone, B. J., . . Lemere, C. A. (2017). Complement C3 deficiency protects against neurodegeneration in aged plaque-rich APP/PS1 mice. Sci Trans/ Med, 9(392). doi:10.1126/scitranslmed.aaf6295

Sieber, M. W., Jaenisch, N., Brehm, M., Guenther, M., Linnartz-Gerlach, B., Neumann, H., ... Frahm, C. (2013). Attenuated inflammatory response in triggering receptor expressed on myeloid cells 2 (TREM2) knock-out mice following stroke. PLoS One, 8(1), e52982. doi:10.1371/journal.pone.0052982

Stevens, B., Allen, N. J., Vazquez, L. E., Howell, G. R., Christopherson, K. S., Nouri, N., . . Barres, B. A. (2007). The classical complement cascade mediates CNS synapse elimination. Cell, 131(6), 11641178. doi:10.1016/j.cell.2007.10.036

Tenner, A. J., Stevens, B., \& Woodruff, T. M. (2018). New tricks for an ancient system: Physiological and pathological roles of complement in the CNS. Mol Immunol, 102, 3-13. doi:10.1016/j.molimm.2018.06.264 
Thion, M. S., \& Garel, S. (2017). On place and time: microglia in embryonic and perinatal brain development. Curr Opin Neurobiol, 47, 121-130. doi:10.1016/j.conb.2017.10.004

Ullian, E. M., Sapperstein, S. K., Christopherson, K. S., \& Barres, B. A. (2001). Control of synapse number by glia. Science, 291(5504), 657-661. doi:10.1126/science.291.5504.657

Ulrich, J. D., Finn, M. B., Wang, Y., Shen, A., Mahan, T. E., Jiang, H., ... Holtzman, D. M. (2014). Altered microglial response to $A \beta$ plaques in APPPS1-21 mice heterozygous for TREM2. Mol Neurodegener, 9(1), 20. doi:10.1186/1750-1326-9-20

Wang, Y., Cella, M., Mallinson, K., Ulrich, J. D., Young, K. L., Robinette, M. L., . . Colonna, M. (2015). TREM2 lipid sensing sustains the microglial response in an Alzheimer's disease model. Cell, 160(6), 1061-1071. doi:10.1016/j.cell.2015.01.049

Wang, Y., Szretter, K. J., Vermi, W., Gilfillan, S., Rossini, C., Cella, M., . . Colonna, M. (2012). IL-34 is a tissue-restricted ligand of CSF1R required for the development of Langerhans cells and microglia. Nat Immunol, 13(8), 753-760. doi:10.1038/ni.2360

Wang, Y., Ulland, T. K., Ulrich, J. D., Song, W., Tzaferis, J. A., Hole, J. T., . . Colonna, M. (2016). TREM2mediated early microglial response limits diffusion and toxicity of amyloid plaques. J Exp Med, 213(5), 667-675. doi:10.1084/jem.20151948

Watkins, L. M., Neal, J. W., Loveless, S., Michailidou, I., Ramaglia, V., Rees, M. I., . . Howell, O. W. (2016). Complement is activated in progressive multiple sclerosis cortical grey matter lesions. J Neuroinflammation, 13(1), 161. doi:10.1186/s12974-016-0611-x

Wyatt, S. K., Witt, T., Barbaro, N. M., Cohen-Gadol, A. A., \& Brewster, A. L. (2017). Enhanced classical complement pathway activation and altered phagocytosis signaling molecules in human epilepsy. Exp Neurol, 295, 184-193. doi:10.1016/j.expneurol.2017.06.009

Xiang, X., Piers, T. M., Wefers, B., Zhu, K., Mallach, A., Brunner, B., ... Haass, C. (2018). The Trem2 R47H Alzheimer's risk variant impairs splicing and reduces Trem2 mRNA and protein in mice but not in 
humans. Mol Neurodegener, 13(1), 49. doi:10.1186/s13024-018-0280-6

Yeh, F. L., Wang, Y., Tom, I., Gonzalez, L. C., \& Sheng, M. (2016). TREM2 Binds to Apolipoproteins, Including APOE and CLU/APOJ, and Thereby Facilitates Uptake of Amyloid-Beta by Microglia. Neuron, 91(2), 328-340. doi:10.1016/j.neuron.2016.06.015

Yuan, P., Condello, C., Keene, C. D., Wang, Y., Bird, T. D., Paul, S. M., . . Grutzendler, J. (2016). TREM2 Haplodeficiency in Mice and Humans Impairs the Microglia Barrier Function Leading to Decreased Amyloid Compaction and Severe Axonal Dystrophy. Neuron, 92(1), 252-264.

doi:10.1016/j.neuron.2016.09.016

Zhao, Y., Wu, X., Li, X., Jiang, L. L., Gui, X., Liu, Y., . . Xu, H. (2018). TREM2 Is a Receptor for beta-Amyloid that Mediates Microglial Function. Neuron, 97(5), 1023-1031.e1027. doi:10.1016/j.neuron.2018.01.031

Zheng, H., Jia, L., Liu, C. C., Rong, Z., Zhong, L., Yang, L., . . Bu, G. (2017). TREM2 Promotes Microglial Survival by Activating Wnt/beta-Catenin Pathway. J Neurosci, 37(7), 1772-1784. doi:10.1523/jneurosci.2459-16.2017

Zhong, L., Wang, Z., Wang, D., Wang, Z., Martens, Y. A., Wu, L., . . Chen, X. F. (2018). Amyloid-beta modulates microglial responses by binding to the triggering receptor expressed on myeloid cells 2 (TREM2). Mol Neurodegener, 13(1), 15. doi:10.1186/s13024-018-0247-7 


\section{TABLES}

Table 1: Regional changes in synaptic elements in 1-month-old Trem2 $^{\%}$ mice

\begin{tabular}{|c|c|c|c|}
\hline & Synaptophysin+ Puncta & PSD95+ Puncta & $\begin{array}{c}\text { Apposed } \\
\text { Synaptic Elements }\end{array}$ \\
\hline Motor CX Layer V & $\begin{array}{c}\downarrow \text { (WT } 0.28 \pm 0.02 \text { vs KO } 0.14 \pm \\
\left.0.02 t_{(7)}=4.31, p=0.0035\right)\end{array}$ & $\begin{array}{c}\downarrow \text { (WT } 0.33 \pm 0.02 \text { vs KO } 0.22 \pm \\
\left.0.04 t_{(7)}=2.15, p=0.0686\right)\end{array}$ & $\begin{array}{c}\downarrow(\text { WT } 0.18 \pm 0.01 \text { vs KO } 0.08 \pm \\
\left.0.02 t_{(7)}=3.90, p=0.0059\right)\end{array}$ \\
\hline $\begin{array}{l}\text { Somatosensory } \\
\text { CX Layer V }\end{array}$ & $\begin{array}{c}\downarrow(\text { WT } 0.27 \pm 0.01 \text { vs KO } 0.17 \pm \\
\left.0.05 t_{(7)}=1.89, p=0.100\right)\end{array}$ & $\begin{array}{c}\leftrightarrow \text { (WT } 0.26 \pm 0.04 \text { vs KO } 0.24 \\
\left. \pm 0.04 t_{(7)}=0.421, p=0.686\right)\end{array}$ & $\begin{aligned} \leftrightarrow & \text { (WT } 0.14 \pm 0.02 \text { vs KO } 0.09 \pm \\
& \left.0.03 t_{(7)}=1.402, p=0.204\right)\end{aligned}$ \\
\hline $\begin{array}{l}\text { Somatosensory } \\
\text { CX Layers II/III }\end{array}$ & $\begin{array}{c}\leftrightarrow(\text { WT } 0.22 \pm 0.01 \text { vs KO } 0.17 \\
\left.\quad \pm 0.03 \mathrm{t}_{(7)}=1.69, p=0.135\right)\end{array}$ & $\begin{array}{c}\leftrightarrow(\mathrm{WT} 0.26 \pm 0.03 \text { vs KO } 0.16 \\
\left. \pm 0.05 \mathrm{t}_{(7)}=1.70, \mathrm{p}=0.133\right)\end{array}$ & $\begin{array}{c}\leftrightarrow \text { (WT } 0.12 \pm 0.01 \text { vs KO } 0.08 \pm \\
\left.0.03 t_{(7)}=1.54, p=0.168\right)\end{array}$ \\
\hline $\begin{array}{l}\text { CA1 Stratum } \\
\text { Radiatum }\end{array}$ & $\begin{array}{c}\downarrow(\text { WT } 0.33 \pm 0.01 \text { vs KO } 0.22 \pm \\
\left.0.05 t_{(7)}=2.40, p=0.047\right)\end{array}$ & $\begin{array}{l}\leftrightarrow(\mathrm{WT} 0.18 \pm 0.06 \text { vs KO } 0.18 \\
\left. \pm 0.10 \mathrm{t}_{(7)}=0.89, p=0.401\right)\end{array}$ & $\begin{array}{c}\downarrow(\text { WT } 0.16 \pm 0.02 \text { vs KO } 0.08 \pm \\
\left.0.03 t_{(7)}=0.2 .03, p=0.089\right)\end{array}$ \\
\hline
\end{tabular}

Data are presented as $\operatorname{Trem}^{+/+}(\mathrm{WT})$ mean \pm SEM vs Trem2 ${ }^{--}(\mathrm{KO})$ mean $\pm \mathrm{SEM}, \mathrm{t}_{\text {(degrees of freedom) }}=\mathrm{t}$ value, $\mathrm{p}=$ $p$ value. Boxes are shaded in conditions where there was a significant $(p<0.05$, dark gray) or a trend toward a significant ( $p<0.10$, light gray) reduction in synaptic elements in Trem $^{-/}$mice relative to Trem2 ${ }^{+/+}$mice. 
Table 2: Regional changes in synaptic element uptake by microglia in 1-month-old Trem2 ${ }^{-/}$mice

\begin{tabular}{|c|c|c|c|}
\hline & $\begin{array}{c}\text { Number of Synapses / } \\
\text { Microglia }\end{array}$ & $\begin{array}{c}\text { Number of Synapses / } \mu^{3}{ }^{3} \\
\text { microglia }\end{array}$ & $\begin{array}{c}\text { Percent Volume of } \\
\text { Synapses in Microglia }\end{array}$ \\
\hline Motor CX Layer V & $\begin{array}{l}\text { 个 (WT } 27.06 \pm 3.74 \text { vs KO } 38.36 \\
\left. \pm 4.67 \mathrm{t}_{(41)}=1.78, \mathrm{p}=0.0829\right)\end{array}$ & $\begin{array}{c}\text { 个(WT } 1.92 \pm 0.23 \text { vs KO } 3.42 \pm \\
\left.0.56 \mathrm{t}_{(42)}=2.14, \mathrm{p}=0.0382\right)\end{array}$ & $\begin{array}{l}\uparrow(W T 0.28 \pm 0.02 \text { vs KO } 0.60 \\
\left. \pm 0.12 t_{(42)}=2.20, p=0.0338\right)\end{array}$ \\
\hline $\begin{array}{c}\text { Motor CX Layers } \\
\text { II/III }\end{array}$ & $\begin{array}{l}\text { 个 (WT } 24.23 \pm 2.15 \text { vs KO } 42.48 \\
\left. \pm 4.91 \mathrm{t}_{(41)}=3.46, p=0.0013\right)\end{array}$ & $\begin{array}{c}\text { 个 (WT } 2.09 \pm 0.18 \text { vs KO } 3.12 \pm \\
\left.0.32 t_{(41)}=2.81, p=0.0077\right)\end{array}$ & $\begin{array}{l}\uparrow(W T 0.28 \pm 0.02 \text { vs KO } 0.41 \\
\left. \pm 0.03 t_{(41)}=3.79, p=0.0005\right)\end{array}$ \\
\hline $\begin{array}{c}\text { Somatosensory } \\
\text { CX Layer V }\end{array}$ & $\begin{array}{c}\leftrightarrow \text { (WT } 41.25 \pm 3.68 \text { vs KO } 38.00 \\
\left. \pm 3.65 t_{(41)}=0.62, p=0.5402\right)\end{array}$ & $\begin{array}{c}\leftrightarrow(\text { WT } 3.32 \pm 0.30 \text { vs KO } 2.90 \pm \\
\left.0.24 t_{(41)}=1.03, p=0.3092\right)\end{array}$ & $\begin{array}{l}\leftrightarrow(\text { WT } 0.40 \pm 0.03 \text { vs KO } 0.36 \\
\left. \pm 0.03 \mathrm{t}_{(42)}=1.42, \mathrm{p}=0.1633\right)\end{array}$ \\
\hline $\begin{array}{c}\text { Somatosensory } \\
\text { CX Layers II/III }\end{array}$ & $\begin{array}{c}\text { 个 (WT } 37.97 \pm 3.86 \text { vs KO } 48.32 \\
\left. \pm 4.08 t_{(50)}=1.81, p=0.0756\right)\end{array}$ & $\begin{array}{c}\leftrightarrow(\mathrm{WT} 11.94 \pm 0.94 \text { vs KO } 11.61 \\
\left. \pm 0.92 \mathrm{t}_{(50)}=0.25, \mathrm{p}=0.8074\right)\end{array}$ & $\begin{array}{l}\leftrightarrow(\text { WT } 1.22 \pm 0.09 \text { vs KO } 1.10 \\
\left. \pm 0.08 t_{(50)}=0.99, p=0.3288\right)\end{array}$ \\
\hline $\begin{array}{c}\text { Posterior Parietal } \\
\text { CX Layer V }\end{array}$ & $\begin{array}{c}\downarrow(W T 7.00 \pm 2.12 \text { vs KO } 3.54 \pm \\
\left.0.81 t_{(19)}=1.79, p=0.0900\right)\end{array}$ & $\begin{array}{c}\leftrightarrow \text { (WT } 3.61 \pm 1.03 \text { vs KO } 2.93 \pm \\
\left.0.65 \mathrm{t}_{(19)}=0.561, p=0.5612\right)\end{array}$ & $\begin{array}{l}\leftrightarrow(\text { WT } 0.56 \pm 0.11 \text { vs KO } 0.44 \\
\left. \pm 0.08 t_{(19)}=0.88, p=0.3914\right)\end{array}$ \\
\hline $\begin{array}{c}\text { Posterior Parietal } \\
\text { CX Layers II/III }\end{array}$ & $\begin{array}{l}\leftrightarrow(\text { WT } 10.20 \pm 1.88 \text { vs KO } 7.80 \\
\left. \pm 0.1 .35 t_{(18)}=1.04, p=0.3140\right)\end{array}$ & $\begin{array}{c}\leftrightarrow(\text { WT } 5.92 \pm 0.95 \text { vs KO } 3.18 \pm \\
\left.1.10 t_{(19)}=2.50, p=0.0218\right)\end{array}$ & $\begin{array}{l}\leftrightarrow(\text { WT } 0.87 \pm 0.12 \text { vs KO } 0.41 \\
\left. \pm 0.07 t_{(19)}=3.11, p=0.0058\right)\end{array}$ \\
\hline $\begin{array}{l}\text { CA1 Stratum } \\
\text { Radiatum } \\
\end{array}$ & $\begin{array}{c}\leftrightarrow(\mathrm{WT} 34.43 \pm 7.15 \text { vs KO } 52.33 \\
\left.\quad \pm 8.18 \mathrm{t}_{(21)}=1.62, \mathrm{p}=0.1211\right)\end{array}$ & $\begin{array}{c}\leftrightarrow(\text { WT } 9.52 \pm 1.66 \text { vs KO } 10.92 \\
\left. \pm 1.08 \mathrm{t}_{(21)}=0.62, \mathrm{p}=0.5423\right)\end{array}$ & $\begin{array}{l}\leftrightarrow(\text { WT } 0.92 \pm 0.14 \text { vs KO } 0.97 \\
\left. \pm 0.07 t_{(21)}=0.33, p=0.7482\right)\end{array}$ \\
\hline Subiculum & $\begin{array}{c}\leftrightarrow(\mathrm{WT} 14.75 \pm 5.46 \text { vs KO } 19.13 \\
\left. \pm 7.44 \mathrm{t}_{(18)}=0.48, \mathrm{p}=0.6337\right)\end{array}$ & $\begin{array}{c}\leftrightarrow \text { (WT } 5.40 \pm 1.77 \text { vs KO } 6.25 \pm \\
\left.1.88 \mathrm{t}_{(18)}=0.32, p=0.7529\right)\end{array}$ & $\begin{array}{l}\leftrightarrow \text { (WT } 0.66 \pm 0.15 \text { vs KO } 1.16 \\
\left. \pm 0.31 t_{(18)}=1.60, p=0.1273\right)\end{array}$ \\
\hline
\end{tabular}

Data are presented as Trem $2^{+/+}(\mathrm{WT})$ mean \pm SEM vs Trem $2^{-/-}(\mathrm{KO})$ mean $\pm \mathrm{SEM}, \mathrm{t}_{\text {(degrees of freedom) }}=\mathrm{t}$ value, $p=p$ value. Boxes are shaded in conditions where there was a significant ( $p<0.05$, dark gray) or a trend toward a significant $\left(p<0.10\right.$, light gray) increase in synaptic elements in Trem2 ${ }^{-/}$mice relative to Trem $2^{+/+}$ mice. 
Table 3: Regional changes in microglia size and morphology in 1-month-old Trem2 ${ }^{-/}$mice

\begin{tabular}{|c|c|c|c|c|}
\hline & Convex Hull Area & Total Intersections & Mean Intersections & Length of Longest Process \\
\hline $\begin{array}{c}\text { Motor CX Layer } \\
\text { V }\end{array}$ & $\begin{array}{c}\text { 个 (WT } 213500 \pm 17660 \text { vs KO } 321600 \pm \\
\left.28970 \mathrm{t}_{(37)}=3.37, \mathrm{p}=0.0018\right)\end{array}$ & $\begin{array}{c}\text { 个 (WT } 89.5 \pm 6.92 \text { vs KO } 115.6 \pm \\
\left.8.86 \mathrm{t}_{(39)}=2.657, \mathrm{p}=0.0114\right)\end{array}$ & $\begin{array}{l}\leftrightarrow \text { (WT } 12.02 \pm 0.68 \text { vs KO } 13.49 \\
\left.\quad \pm 0.59 \mathrm{t}_{(38)}=1.52, \mathrm{p}=0.1378\right)\end{array}$ & $\begin{array}{c}\text { 个 (WT } 38.11 \pm 1.72 \text { vs KO } 47.78 \pm \\
\left.2.78 t_{(38)}=3.13, p=0.0033\right)\end{array}$ \\
\hline $\begin{array}{c}\text { Motor CX } \\
\text { Layers II/III }\end{array}$ & $\begin{array}{c}\leftrightarrow(\mathrm{WT} 235400 \pm 17750 \text { vs KO } 236800 \\
\left.\quad \pm 19270 \mathrm{t}_{(39)}=0.05, \mathrm{p}=0.9576\right)\end{array}$ & $\begin{array}{c}\leftrightarrow \text { (WT } 69.05 \pm 6.49 \text { vs KO } 63.26 \pm \\
\left.5.31 \mathrm{t}_{(39)}=0.67, p=0.5028\right)\end{array}$ & $\begin{array}{c}\leftrightarrow \quad(\text { WT } 9.86 \pm 0.73 \text { vs KO } 8.76 \pm \\
\left.0.53 t_{(39)}=1.19, p=0.2428\right)\end{array}$ & $\begin{array}{c}\leftrightarrow(\text { WT } 38.24 \pm 1.89 \text { vs KO } 41.59 \pm \\
\left.2.00 t_{(39)}=1.23, p=0.2278\right)\end{array}$ \\
\hline $\begin{array}{l}\text { Motor CX } \\
\text { Average }\end{array}$ & $\begin{array}{c}\text { 个 (WT } 224200 \pm 12490 \text { vs KO } 275600 \pm \\
\left.18120 t_{(78)}=2.41, p=0.0185\right)\end{array}$ & $\begin{array}{c}\leftrightarrow(\text { WT } 78.02 \pm 4.88 \text { vs KO } 87.20 \pm \\
\left.6.63 \mathrm{t}_{(80)}=1.14, \mathrm{p}=0.2571\right)\end{array}$ & $\begin{array}{l}\leftrightarrow(\mathrm{WT} 10.99 \pm 0.52 \text { vs KO } 10.92 \\
\left.\quad \pm 0.56 \mathrm{t}_{(79)}=0.09, \mathrm{p}=0.9310\right)\end{array}$ & $\begin{array}{c}\text { 个 (WT } 38.17 \pm 1.25 \text { vs KO } 44.42 \pm \\
\left.1.73 t_{790)}=3.01, p=0.0035\right)\end{array}$ \\
\hline $\begin{array}{c}\text { Posterior } \\
\text { Parietal CX } \\
\text { Layer V }\end{array}$ & $\begin{array}{c}\downarrow(\text { WT } 177100 \pm 11590 \text { vs KO } 145900 \pm \\
\left.6908 t_{(21)}=2.44, p=0.0238\right)\end{array}$ & $\begin{array}{c}\downarrow(\text { WT } 58.10 \pm 3.35 \text { vs KO } 42.31 \pm \\
\left.2.82 \mathrm{t}_{(21)}=3.63, \mathrm{p}=0.0016\right)\end{array}$ & $\begin{array}{c}\downarrow(\text { WT } 10.01 \pm 0.89 \text { vs KO } 8.20 \pm \\
\left.0.57 t_{(21)}=1.78, p=0.0889\right)\end{array}$ & $\begin{array}{c}\leftrightarrow(\text { WT } 43.01 \pm 2.23 \text { vs KO } 47.35 \pm \\
\left.3.05 \mathrm{t}_{(21)}=1.17, \mathrm{p}=0.2538\right)\end{array}$ \\
\hline $\begin{array}{c}\text { Posterior } \\
\text { Parietal CX } \\
\text { Layers II/III }\end{array}$ & $\begin{aligned} \leftrightarrow & (W T 172400 \pm 10930 \text { vs KO } 184700 \\
& \left. \pm 12480 \mathrm{t}_{(19)}=0.75, p=0.4647\right)\end{aligned}$ & $\begin{array}{c}\leftrightarrow(W T 51.09 \pm 2.85 \text { vs KO } 53.50 \pm \\
\left.2.80 \mathrm{t}_{(19)}=0.60, p=0.5552\right)\end{array}$ & $\begin{array}{c}\leftrightarrow(\text { WT } 9.10 \pm 0.66 \text { vs KO } 9.97 \pm \\
\left.0.62 \mathrm{t}_{(19)}=0.95, p=0.3558\right)\end{array}$ & $\begin{array}{c}\leftrightarrow(\text { WT } 32.86 \pm 1.59 \text { vs KO } 32.37 \pm \\
\left.1.76 \mathrm{t}_{(19)}=0.21, \mathrm{p}=0.8380\right)\end{array}$ \\
\hline $\begin{array}{c}\text { Posterior } \\
\text { Parietal CX } \\
\text { Average }\end{array}$ & $\begin{array}{c}\leftrightarrow(\text { WT } 174600 \pm 7767 \text { vs KO } 162800 \pm \\
\left.7699 \mathrm{t}_{(42)}=1.09, \mathrm{p}=0.2840\right)\end{array}$ & $\begin{array}{c}\downarrow(\text { WT } 54.43 \pm 2.27 \text { vs KO } 47.17 \pm \\
\left.2.29 \mathrm{t}_{(42)}=2.25, \mathrm{p}=0.0301\right)\end{array}$ & $\begin{array}{c}\leftrightarrow(\text { WT } 9.54 \pm 0.55 \text { vs KO } 8.97 \pm \\
\left.0.45 t_{(42)}=0.81, p=0.4220\right)\end{array}$ & $\begin{aligned} \leftrightarrow & (\text { WT } 33.26 \pm 1.40 \text { vs KO } 31.90 \pm \\
& \left.0.91 \mathrm{t}_{(42)}=0.83, p=0.4117\right)\end{aligned}$ \\
\hline $\begin{array}{l}\text { CA1 Stratum } \\
\text { Radiatum }\end{array}$ & $\begin{array}{c}\text { 个 (WT } 219100 \pm 14970 \text { vs KO } 298300 \pm \\
\left.27710 t_{(21)}=2.74, p=0.0122\right)\end{array}$ & $\begin{array}{c}\text { 个 (WT } 68.64 \pm 4.02 \text { vs KO } 97.44 \pm \\
\left.10.18 t_{(21)}=3.03, p=0.0064\right)\end{array}$ & $\begin{array}{c}\text { 个 (WT } 9.41 \pm 0.47 \text { vs KO } 11.45 \pm \\
\left.0.81 t_{(21)}=2.34, p=0.0291\right)\end{array}$ & $\begin{array}{c}\leftrightarrow(\text { WT } 43.01 \pm 2.23 \text { vs KO } 47.35 \pm \\
\left.3.05 t_{(21)}=1.17, p=0.2538\right)\end{array}$ \\
\hline
\end{tabular}

Data are presented as Trem2 $2^{+/}(\mathrm{WT})$ mean \pm SEM vs Trem $2^{-/}(\mathrm{KO})$ mean $\pm \mathrm{SEM}, \mathrm{t}_{\text {(degrees of freedom) }}=\mathrm{t}$ value, $\mathrm{p}=\mathrm{p}$ value. Boxes are shaded in conditions where there was a significant increase ( $p<0.05$, dark green), a significant decrease ( $<<0.05$, dark pink) or a trend toward a significant decrease ( $p<0.05$, light pink) in the features of microglia listed above in Trem $2^{-/}$mice relative to Trem2 ${ }^{+/+}$mice. 
Table 4: Regional changes in synaptic element uptake by astrocytes in 1-month-old Trem2 $\%$ mice

\begin{tabular}{|c|c|c|}
\hline & $\begin{array}{c}\text { Number of Synapses / } \\
\mu^{3} \text { Astrocyte }\end{array}$ & $\begin{array}{c}\text { Percent Volume of } \\
\text { Synapses in Astrocytes }\end{array}$ \\
\hline Motor CX Layer V & $\begin{array}{c}\text { 个 (WT } 6.39 \pm 0.78 \text { vs KO } 9.22 \pm \\
\left.0.69 t_{(29)}=2.70, p=0.0114\right)\end{array}$ & $\begin{array}{l}\text { 个 (WT } 0.78 \pm 0.08 \text { vs KO } 1.13 \\
\left. \pm 0.13 \mathrm{t}_{(29)}=2.43, p=0.0214\right)\end{array}$ \\
\hline $\begin{array}{c}\text { Motor CX Layers } \\
\text { II/III }\end{array}$ & $\begin{array}{c}\leftrightarrow \text { (WT } 12.91 \pm 1.81 \text { vs KO } \\
16.86 \pm 2.51 \mathrm{t}_{(13)}=1.24, \mathrm{p}= \\
0.2365)\end{array}$ & $\begin{array}{l}\leftrightarrow(\text { WT } 1.87 \pm 0.31 \text { vs KO } 2.30 \\
\left. \pm 0.41 t_{(13)}=0.81, p=0.4338\right)\end{array}$ \\
\hline $\begin{array}{c}\text { Somatosensory } \\
\text { CX Layer V }\end{array}$ & $\begin{array}{c}\text { 个 (WT } 9.11 \pm 0.97 \text { vs KO } 22.44 \pm \\
\left.3.60 t_{(11)}=3.32, p=0.0068\right)\end{array}$ & $\begin{array}{l}\uparrow(W T 1.26 \pm 0.15 \text { vs KO } 2.90 \\
\left. \pm 0.50 t_{(11)}=2.95, p=0.0132\right)\end{array}$ \\
\hline $\begin{array}{l}\text { Somatosensory } \\
\text { CX Layers II/III }\end{array}$ & $\begin{array}{c}\leftrightarrow \text { (WT } 19.06 \pm 5.55 \text { vs KO } \\
17.50 \pm 1.86 \mathrm{t}_{(13)}=0.28, \mathrm{p}= \\
0.7819)\end{array}$ & $\begin{array}{l}\leftrightarrow(\text { WT } 2.69 \pm 0.82 \text { vs KO } 2.15 \\
\left. \pm 0.24 t_{(13)}=0.67, p=0.5131\right)\end{array}$ \\
\hline $\begin{array}{l}\text { Posterior Parietal } \\
\text { CX Layer V }\end{array}$ & $\begin{array}{c}\leftrightarrow(\mathrm{WT} 15.44 \pm 1.65 \text { vs KO } \\
25.29 \pm 5.52 \mathrm{t}_{(5)}=1.96, \mathrm{p}= \\
0.1069)\end{array}$ & $\begin{array}{c}\leftrightarrow \text { (WT } 2.22 \pm 0.23 \text { vs KO } 3.33 \\
\left. \pm 0.77 t_{(5)}=1.60, p=0.1698\right)\end{array}$ \\
\hline $\begin{array}{l}\text { Posterior Parietal } \\
\text { CX Layers II/III }\end{array}$ & $\begin{array}{c}\leftrightarrow \text { (WT } 13.93 \pm 0.44 \text { vs KO } \\
22.47 \pm 4.64 t_{(4)}=1.83, p= \\
0.1407)\end{array}$ & $\begin{array}{c}\leftrightarrow \text { (WT } 1.44 \pm 0.27 \text { vs KO } 2.08 \\
\left. \pm 0.31 t_{(5)}=1.54, p=0.1843\right)\end{array}$ \\
\hline $\begin{array}{l}\text { CA1 Stratum } \\
\text { Radiatum }\end{array}$ & $\begin{array}{c}\text { 个 (WT } 15.77 \pm 0.50 \text { vs KO } 46.53 \\
\left. \pm 8.18 \mathrm{t}_{(6)}=2.82, \mathrm{p}=0.0304\right)\end{array}$ & $\begin{array}{l}\text { 个 (WT } 1.67 \pm 0.30 \text { vs KO } 5.45 \\
\left. \pm 1.03 t_{(7)}=3.16, p=0.0159\right)\end{array}$ \\
\hline Subiculum & $\begin{array}{c}\leftrightarrow \text { (WT } 13.51 \pm 3.35 \text { vs KO } \\
22.01 \pm 3.20 t_{(8)}=1.77, p= \\
0.1142)\end{array}$ & $\begin{array}{c}\leftrightarrow(\mathrm{WT} 1.87 \pm 0.48 \text { vs KO } 2.82 \\
\left. \pm 0.44 \mathrm{t}_{(8)}=1.42, \mathrm{p}=0.1925\right)\end{array}$ \\
\hline
\end{tabular}

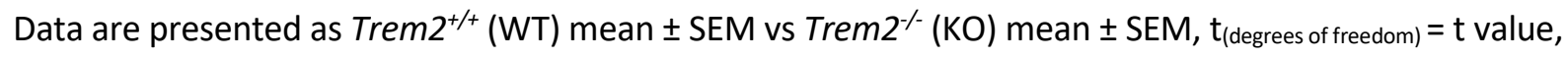
$p=p$ value. Boxes are shaded in conditions where there was a significant $(p<0.05$, dark gray) increase in synaptic elements in astrocytes in $\mathrm{Trem}^{-/}$mice relative to $\mathrm{Trem}^{+/+}$mice. 
Table 5: Regional changes in synaptic element uptake by microglia in 4-month-old Trem $^{-/-}$mice

\begin{tabular}{|c|c|c|c|}
\hline & $\begin{array}{c}\text { Number of Synapses / } \\
\text { Microglia }\end{array}$ & $\begin{array}{c}\text { Number of Synapses } \\
\qquad / \mu \mathrm{m}^{3} \text { microglia }\end{array}$ & $\begin{array}{c}\text { Percent Volume of } \\
\text { Synapses in Microglia }\end{array}$ \\
\hline Motor CX Layer V & $\begin{array}{c}\leftrightarrow(\text { WT } 118.8 \pm 9.20 \text { vs KO } \\
100.9 \pm 10.58 \mathrm{t}_{(67)}=1.27, \mathrm{p}= \\
0.2078)\end{array}$ & $\begin{array}{c}\downarrow(\text { WT } 29.71 \pm 1.64 \text { vs KO } \\
23.42 \pm 1.91 \mathrm{t}_{(68)}=2.51, \mathrm{p}= \\
0.0146)\end{array}$ & $\begin{array}{c}\leftrightarrow \text { (WT } 3.44 \pm 0.22 \text { vs KO } \\
3.02 \pm 0.29 t_{(66)}=1.19, p= \\
0.2381)\end{array}$ \\
\hline $\begin{array}{l}\text { Motor CX Layer V } \\
\text { (Excluding Large } \\
\text { Inclusions) }\end{array}$ & $\begin{array}{c}\downarrow(\text { WT } 85.98 \pm 7.02 \text { vs KO } 66.97 \\
\left. \pm 7.82 t_{(67)}=1.79, p=0.0775\right)\end{array}$ & $\begin{array}{c}\downarrow(\text { WT } 21.34 \pm 1.22 \text { vs KO } \\
15.48 \pm 1.43 t_{(68)}=3.13, p= \\
0.0025)\end{array}$ & $\begin{array}{l}\downarrow \text { (WT } 0.97 \pm 0.06 \text { vs KO } 0.71 \\
\left. \pm 0.06 t_{(67)}=3.02, p=0.0036\right)\end{array}$ \\
\hline CA1 Stratum Radiatum & $\begin{array}{l}\downarrow(\text { WT } 48.88 \pm 6.02 \text { vs KO } 65.09 \\
\left. \pm 5.50 t_{(54)}=1.97, p=0.0535\right)\end{array}$ & $\begin{array}{c}\downarrow(W T 18.15 \pm 1.82 \text { vs KO } \\
21.78 \pm 1.24 t_{(54)}=1.71, p= \\
0.0931)\end{array}$ & $\begin{array}{c}\leftrightarrow \text { (WT } 1.99 \pm 0.16 \text { vs KO } \\
1.84 \pm 0.11 t_{(53)}=0.79, p= \\
0.4356)\end{array}$ \\
\hline $\begin{array}{l}\text { CA1 Stratum Radiatum } \\
\text { (Excluding Large } \\
\text { Inclusions) }\end{array}$ & $\begin{array}{l}\downarrow(\text { WT } 39.63 \pm 5.45 \text { vs KO } 53.75 \\
\left. \pm 4.74 t_{(54)}=1.96, p=0.0558\right)\end{array}$ & $\begin{array}{c}\downarrow \text { (WT } 14.51 \pm 1.66 \text { vs KO } \\
17.84 \pm 1.12 \mathrm{t}_{(54)}=1.72, \mathrm{p}= \\
0.0909)\end{array}$ & $\begin{array}{l}\downarrow(W T 0.61 \pm 0.06 \text { vs KO } 0.73 \\
\left. \pm 0.04 t_{(54)}=1.72, p=0.0916\right)\end{array}$ \\
\hline
\end{tabular}

Data are presented as Trem2 $2^{+/+}(\mathrm{WT})$ mean \pm SEM vs Trem2 ${ }^{-/}(\mathrm{KO})$ mean $\pm \mathrm{SEM}, \mathrm{t}_{\text {(degrees of freedom) }}=\mathrm{t}$ value, $p=p$ value. Boxes are shaded in conditions where there was a significant $(p<0.05$, dark gray) or a trend toward a significant $\left(p<0.10\right.$, light gray) decrease in synaptic elements in microglia in Trem $2^{-/}$mice relative to $\mathrm{Trem}^{+/+}$mice. 
Table 6: Regional changes in microglia size and morphology in 4-month-old Trem2\% mice

\begin{tabular}{|c|c|c|c|c|}
\hline & Convex Hull Area & Total Intersections & Mean Intersections & Length of Longest Process \\
\hline $\begin{array}{c}\text { Motor CX Layer } \\
\text { V }\end{array}$ & $\begin{array}{c}\leftrightarrow(W T 231400 \pm 14470 \text { vs KO } \\
262500 \pm 19530 \mathrm{t}_{(68)}=1.31, p= \\
0.1961)\end{array}$ & $\begin{array}{c}\leftrightarrow \text { (WT } 74.15 \pm 4.75 \text { vs KO } \\
81.47 \pm 6.44 \mathrm{t}_{(68)}=0.94, p= \\
0.3625)\end{array}$ & $\begin{array}{c}\leftrightarrow(W T 9.74 \pm 0.48 \text { vs KO } 10.11 \\
\left. \pm 0.59 t_{(68)}=0.49, p=0.6238\right)\end{array}$ & $\begin{array}{c}\leftrightarrow \text { (WT } 42.34 \pm 1.59 \text { vs KO } 45.02 \\
\left. \pm 1.95 \mathrm{t}_{(68)}=1.08, p=0.2860\right)\end{array}$ \\
\hline $\begin{array}{l}\text { CA1 Stratum } \\
\text { Radiatum }\end{array}$ & $\begin{array}{c}\leftrightarrow(W T 242900 \pm 15460 \text { vs KO } \\
232500 \pm 11570 \mathrm{t}_{(56)}=0.55, p= \\
0.5852)\end{array}$ & $\begin{array}{c}\leftrightarrow(W T 71.19 \pm 5.77 \text { vs KO } \\
65.50 \pm 3.42 \mathrm{t}_{(56)}=0.88, p= \\
0.3804)\end{array}$ & $\begin{array}{c}\leftrightarrow(\mathrm{WT} 10.07 \pm 0.62 \text { vs KO } 9.25 \\
\left. \pm 0.44 \mathrm{t}_{(56)}=1.10, p=0.2779\right)\end{array}$ & $\begin{array}{l}\leftrightarrow \text { (WT } 40.41 \pm 1.44 \text { vs KO } 40.25 \\
\left.\quad \pm 1.18 \mathrm{t}_{(55)}=0.08, p=0.9326\right)\end{array}$ \\
\hline
\end{tabular}

Data are presented as Trem2 $2^{+/+}(\mathrm{WT})$ mean \pm SEM vs Trem $2^{-/}\left(\right.$KO) mean \pm SEM, $t_{\text {(degrees of freedom })}=t$ value, $p=p$ value. 
Table 7: Regional changes in synaptic element uptake by astrocytes in 4-month-old

Trem2\% mice

\begin{tabular}{|ccc|}
\hline & $\begin{array}{c}\text { Number of Synapses } / \boldsymbol{\mu m}^{3} \\
\text { Astrocyte }\end{array}$ & $\begin{array}{c}\text { Percent Volume of } \\
\text { Synapses in Astrocytes }\end{array}$ \\
\hline Motor CX Layer & $\leftrightarrow(\mathrm{WT} 13.88 \pm 1.08$ vs KO 14.18 & $\leftrightarrow(\mathrm{WT} 1.70 \pm 0.12$ vs KO 1.96 \\
$\mathbf{V}$ & $\left.\pm 1.46 \mathrm{t}_{(42)}=0.17, \mathrm{p}=0.8693\right)$ & $\left.\pm 0.16 \mathrm{t}_{(42)}=1.28, \mathrm{p}=0.21\right)$ \\
\hline CA1 Stratum & $\uparrow(\mathrm{WT} 14.92 \pm 0.93$ vs KO 20.21 \pm & $\uparrow(\mathrm{WT} 2.21 \pm 0.10$ vs KO 2.83 \pm \\
Radiatum & $\left.1.54 \mathrm{t}_{(40)}=3.09, \mathrm{p}=0.0037\right)$ & $\left.0.19 \mathrm{t}_{(40)}=3.06, \mathrm{p}=0.0040\right)$ \\
\hline
\end{tabular}

Data are presented as Trem2 $2^{+/}(\mathrm{WT})$ mean \pm SEM vs Trem $2^{-/}(\mathrm{KO})$ mean $\pm \mathrm{SEM}, \mathrm{t}_{\text {(degrees of freedom) }}=\mathrm{t}$ value, $\mathrm{p}=$ $p$ value. Boxes are shaded in conditions where there was a significant $(p<0.05$, dark gray) increase in synaptic elements in Trem2 $^{--}$mice relative to Trem2 $^{+/+}$mice. 
Figure 1
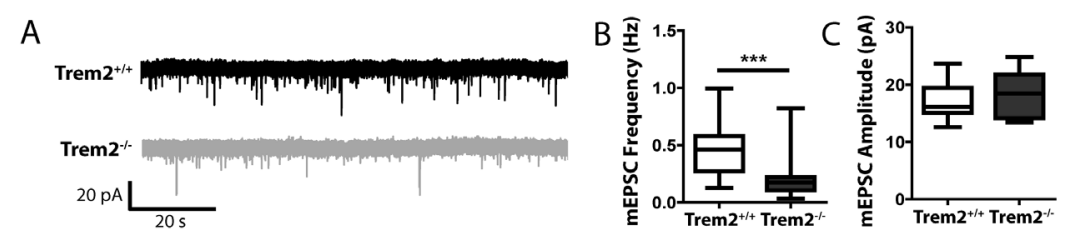

D

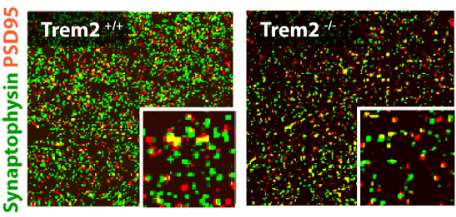

E

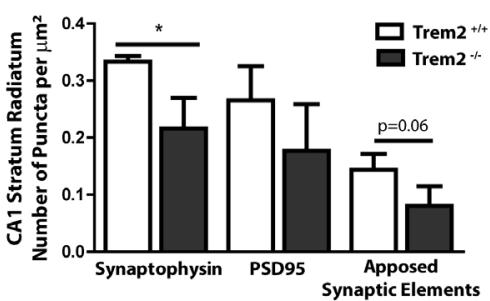

F

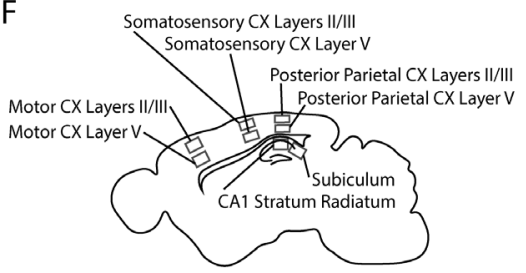

G
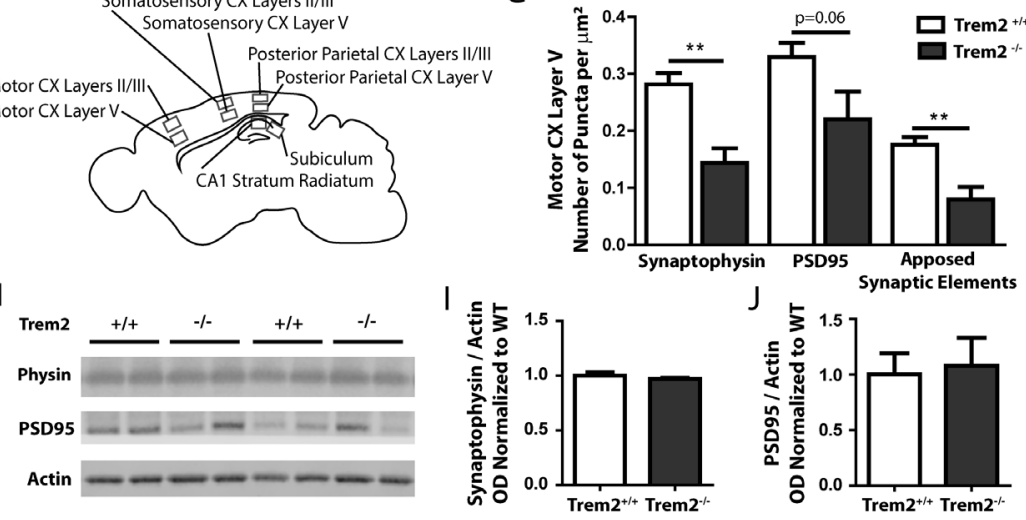

Figure 1. TREM2 deficiency results in reduced synapse number (A) Whole cell patch clamp recordings of CA1 pyramidal neurons in hippocampal slices from 1-1.5-month-old Trem2 ${ }^{+/+}$and Trem2 ${ }^{-/}$mice revealed (B) significant reductions in mEPSC frequency in Trem2 ${ }^{-}$mice (C) with no change in mEPSC amplitude. (D) Staining for synaptophysin (green) and PSD95 (red) was used to assess synapse number in 1-month-old Trem2 $^{+/+}$and Trem2 ${ }^{--}$mice. (E) In CA1 stratum radiatum, there was a significant reduction in the number of synaptophysin+ puncta and a trend toward a reduction in apposed synaptic elements, as measured by PSD95+ puncta within $0.5 \mu \mathrm{m}$ of synaptophysin+ puncta. (F) Synaptic changes were also investigated in other regions of the mouse brain. (G) In layer $V$ of the motor cortex, there was a significant 
reduction in synaptophysin+ puncta, a strong trend toward a reduction in PSD95+ puncta and a significant decrease in apposed synaptic elements. $(\mathrm{H})$ Western blots were performed on synaptosome enriched fractions isolated from whole brains of 1-month-old Trem $2^{+/+}$and Trem2 $2^{--}$mice. (I) Within these synaptosomal fractions, there was no change in the abundance of synaptophysin or (J) PSD95 protein levels. ${ }^{*}(p<0.05), * *(p<0.01), * * *(p<0.001)$

\section{Supplemental Figure 1}

A

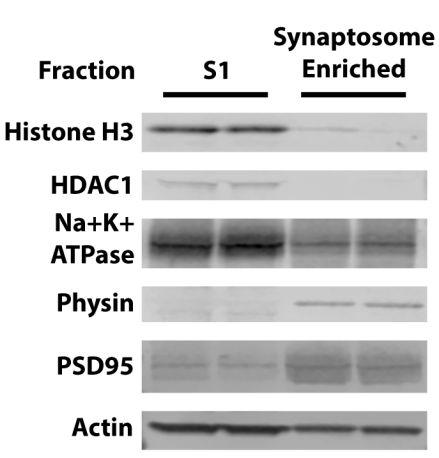

B
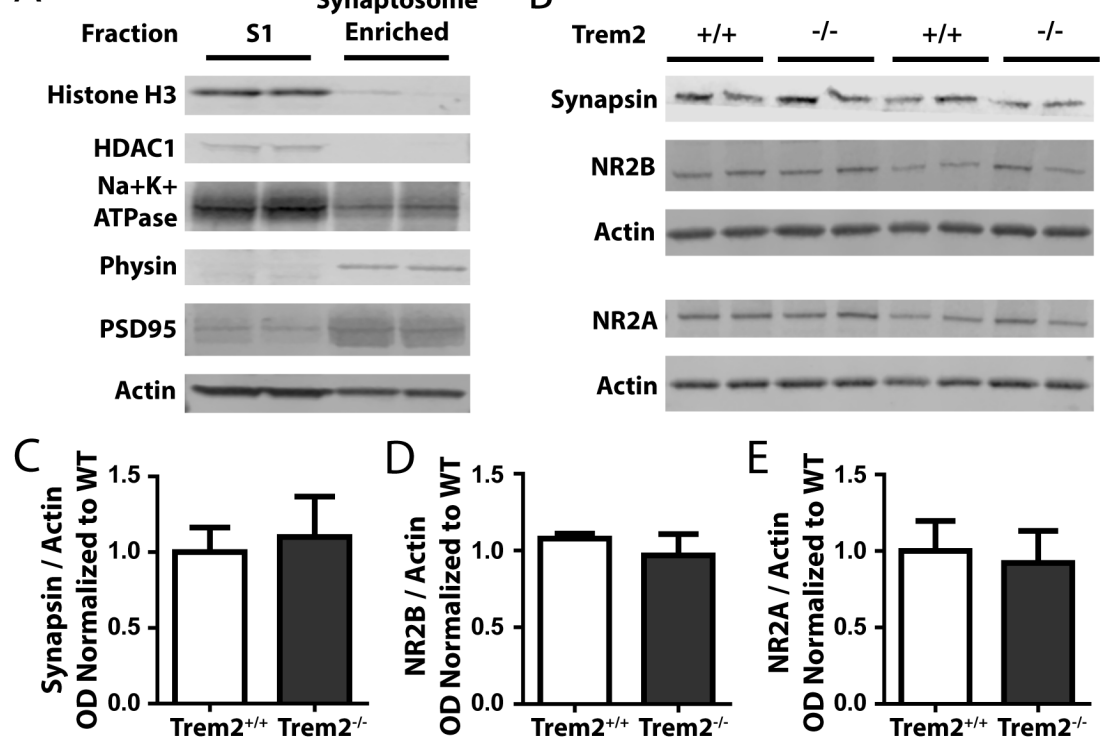

Figure S1. (A) Enrichment of synaptosomal proteins was validated in lysates prepared from synaptosomal isolations from Trem2 $^{+/+}$and Trem2 $2^{-/}$mouse brains (synaptosome enriched) relative to whole protein lysates (S1). (B) Western blots were performed on synaptosome enriched fractions to assess protein levels of (C) synapsin, (D) NR2B and (E) NR2A. 
Figure 2

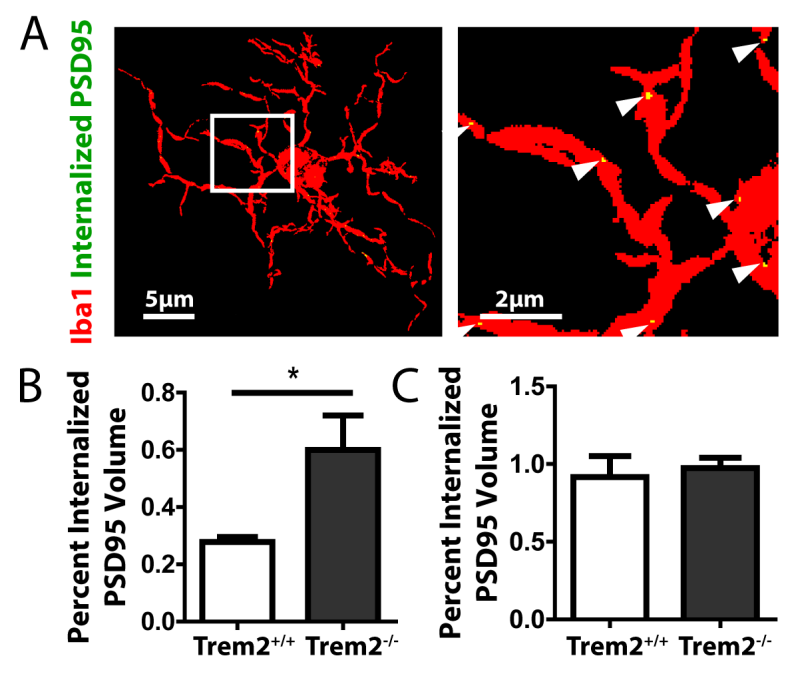

Figure 2. TREM2 deficient microglia contain more engulfed synaptic material. (A) Confocal images of microglia (Iba1, red) and PSD95 (green) were acquired in layer $\mathrm{V}$ of the motor cortex. Images were thresholded and binary images were used to reconstruct individual microglia and PSD95 that was internalized within the microglial cell volume (indicated by white arrows). (B) The percent of Iba1+ cell volume that contained PSD95+ elements was significantly increased in layer $\mathrm{V}$ of the motor cortex in Trem $^{-/}$mice relative to $\mathrm{Trem}^{+/+}$controls at 1 month of age. (C) There were no differences in internalized PSD95 volume in CA1 stratum radiatum. * $(p<0.05)$ 
Supplemental Figure 2

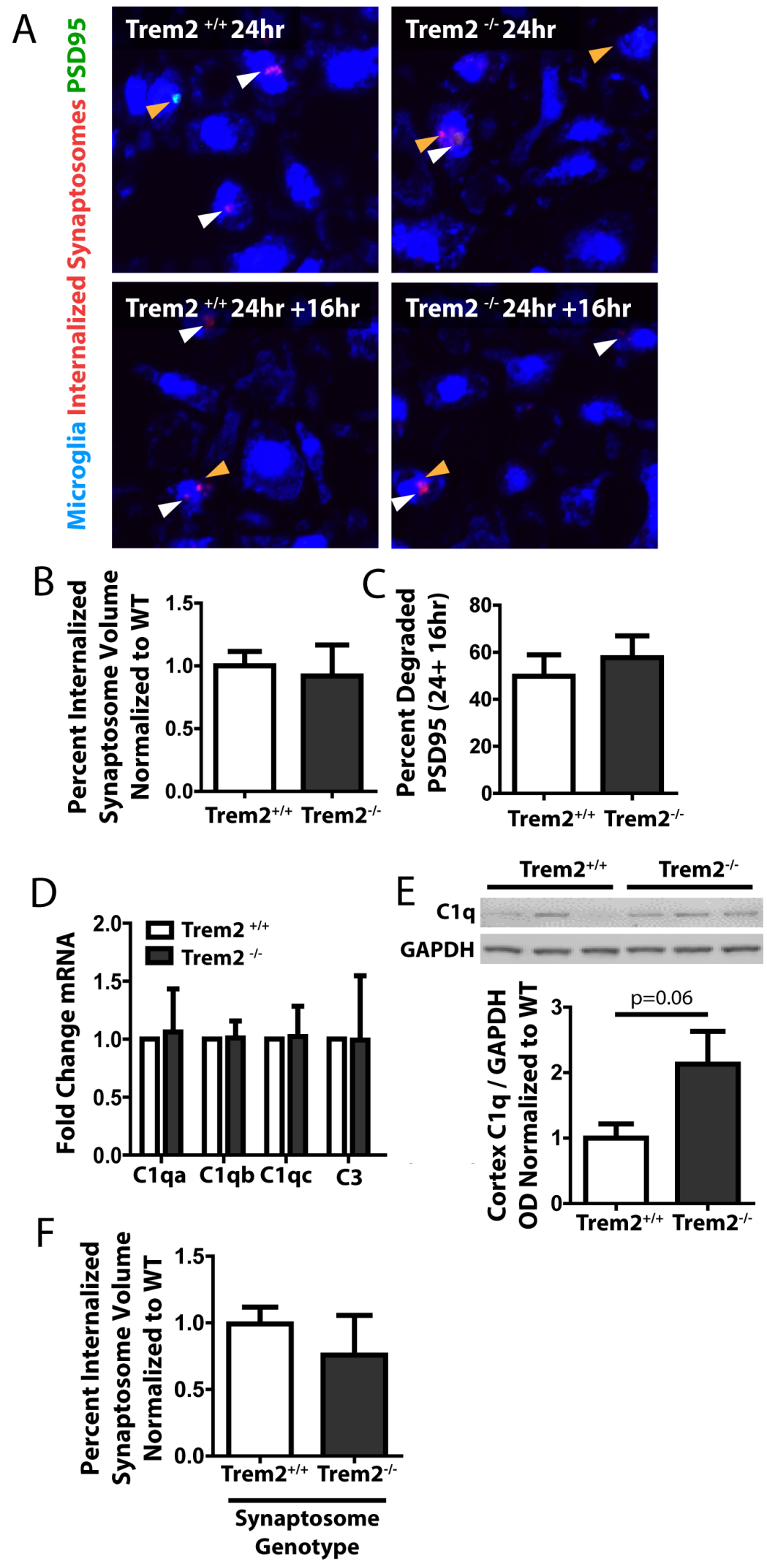


Figure S2. (A) Primary microglia were isolated from littermate Trem2 ${ }^{+/+}$and $T r e m 2^{-/}$pups, cells were labeled with CellTracker (blue) and then exposed to Trem2 ${ }^{+/+}$pHrodo conjugated synaptosomes (red) for 24 hours. Cells were either fixed (24hr) or switched to fresh media and fixed after an additional $16 \mathrm{hr}$ (24hr + 16hr) and stained with PSD95 (green). White arrows indicate internalized synaptosomes and yellow arrows internalized synaptosomes which also co-localized with PSD95. (B) There was no significant effect of Trem2 genotype on the percent of microglial volume comprised of isolated synaptosomes after 24 hours or (C) the percent of internalized PSD95 signal that was degraded after an additional 16hr. (D) qPCR was used to assess gene expression levels of complement components. (E) Western blots were performed on cortical lysates to evaluate levels of C1q protein expression relative to GAPDH. (F) $\operatorname{Trem}^{+/+}$microglia were cultured and exposed to pHrodo conjugated synaptosomes isolated from brains of 1-month-old Trem $^{+/+}$or Trem2 ${ }^{-/-}$mice and the percent internalized synaptosome volume quantified after 24 hours as in (A). 
Figure 3
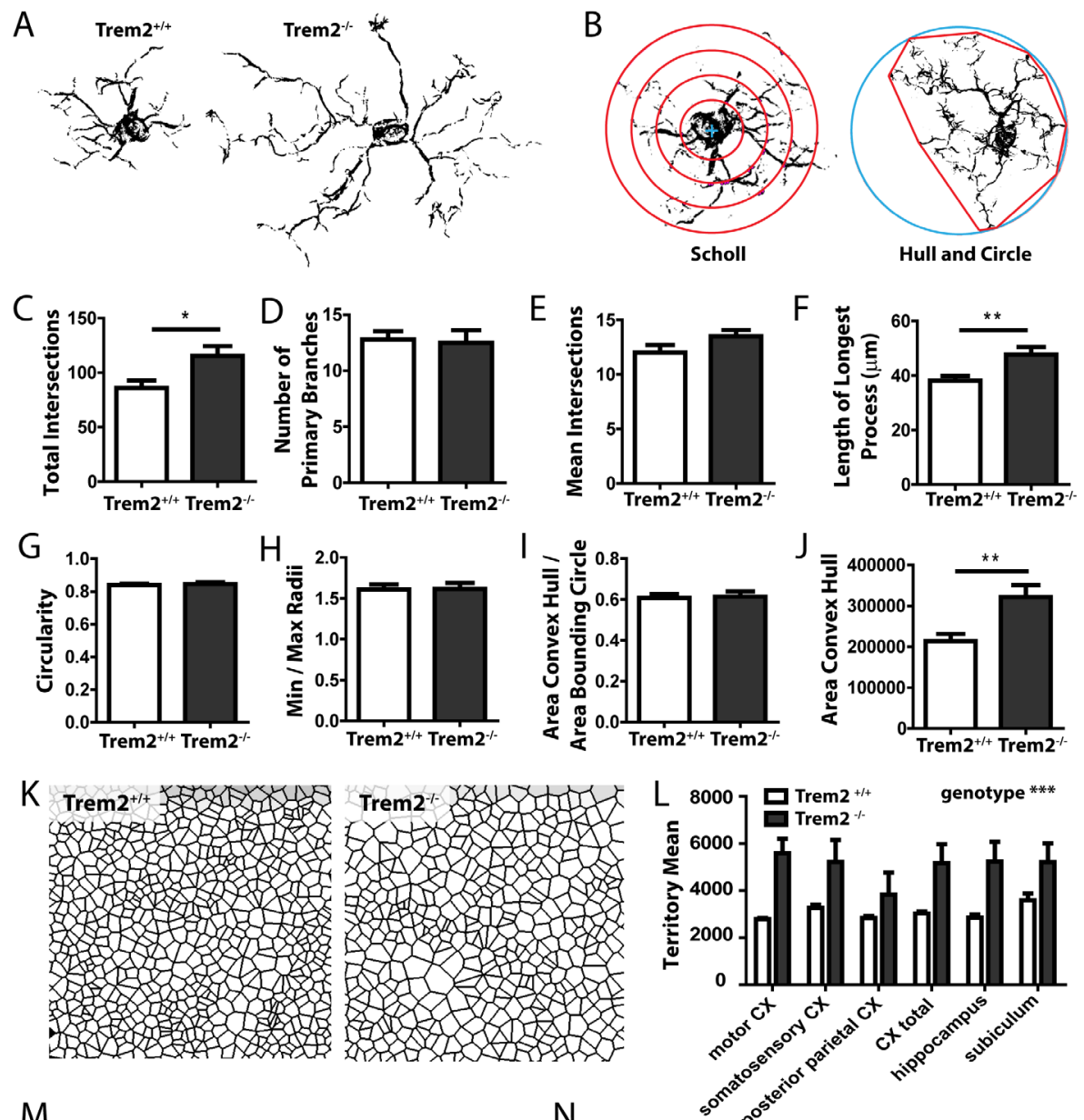

M

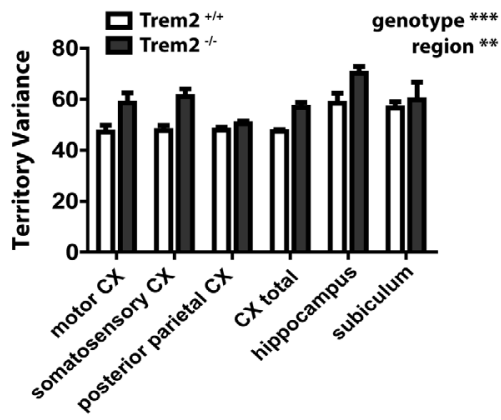

O

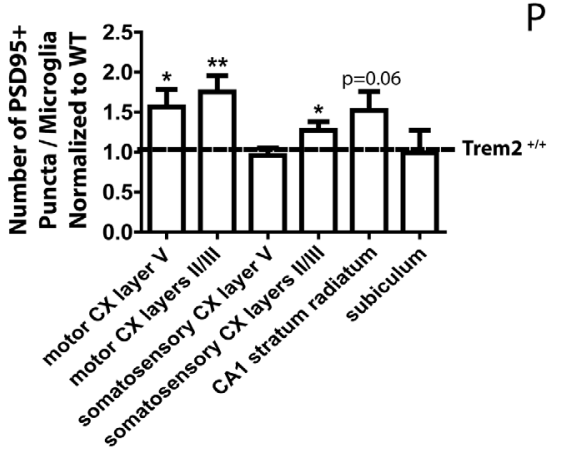

N

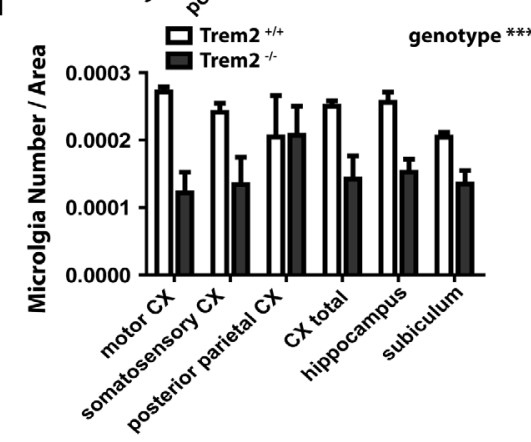

P

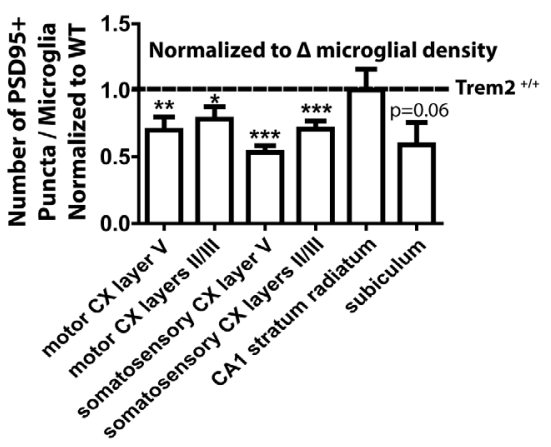


Figure 3. TREM2 is required for establishing appropriate microglial size, territory and number. (A) Morphology of individual microglia from 1-month-old Trem $^{+/+}$and $\mathrm{Trem}^{-/-}$mice was quantified (B) using Scholl and hull and circle analyses. (C) In layer $V$ of the motor cortex, there was a significant increase in the total number of intersections in Trem $2^{-/}$microglia identified using Sholl analysis, with (D) no change in the number of primary branches or (E) the mean number of branches intersecting with each Sholl radius. (F) The length of the longest process was significantly increased in Trem2 $2^{--}$microglia. (G) Hull and circle analysis identified no changes in microglial branch distribution in Trem $2^{--}$microglia as measured by circularity, $(\mathrm{H})$ a ratio of the minimum to maximum radii that could be drawn through the convex hull, or (I) the ratio of the area of the convex hull to its circumscribing circle. (J) The average area of the convex hull containing Trem2 ${ }^{-/}$microglia was significantly larger than Trem2 $2^{+/+}$microglia. (K) Microglial cell bodies were identified and used as seeds to produce Voronnoi tessellations to estimate the territory of individual microglia across the cortex and hippocampus. (L) The average size of these territories was quantified (M) along with the territory variance, calculated as the coefficient of variance for all the microglial territories defined within a given brain region for each animal. $(\mathrm{N})$ The number of Iba1+ microglia was quantified across the cortex and hippocampus. (0) The number of internalized PSD95+ elements was quantified per microglia across the indicated brain regions and $T r e m 2^{--}$data normalized to $T r e m 2^{+/+}$results within each region. Asterisks indicate results which were significantly different from 1. (P) The number of PSD95+ elements per cell was normalized to the difference in microglial density between $\mathrm{Trem}^{+/+}$and Trem2 ${ }^{-/-}$ mice in each brain region, determined from the quantification performed in $(\mathrm{N})$. Asterisks indicate results which are significantly different from 1 . Statistical results of 2-way ANOVAs are indicated, where significant, above graphs. ${ }^{*}(p<0.05),{ }^{* *}(p<0.01), * * *(p<0.001)$ 


\section{Supplemental Figure 3}

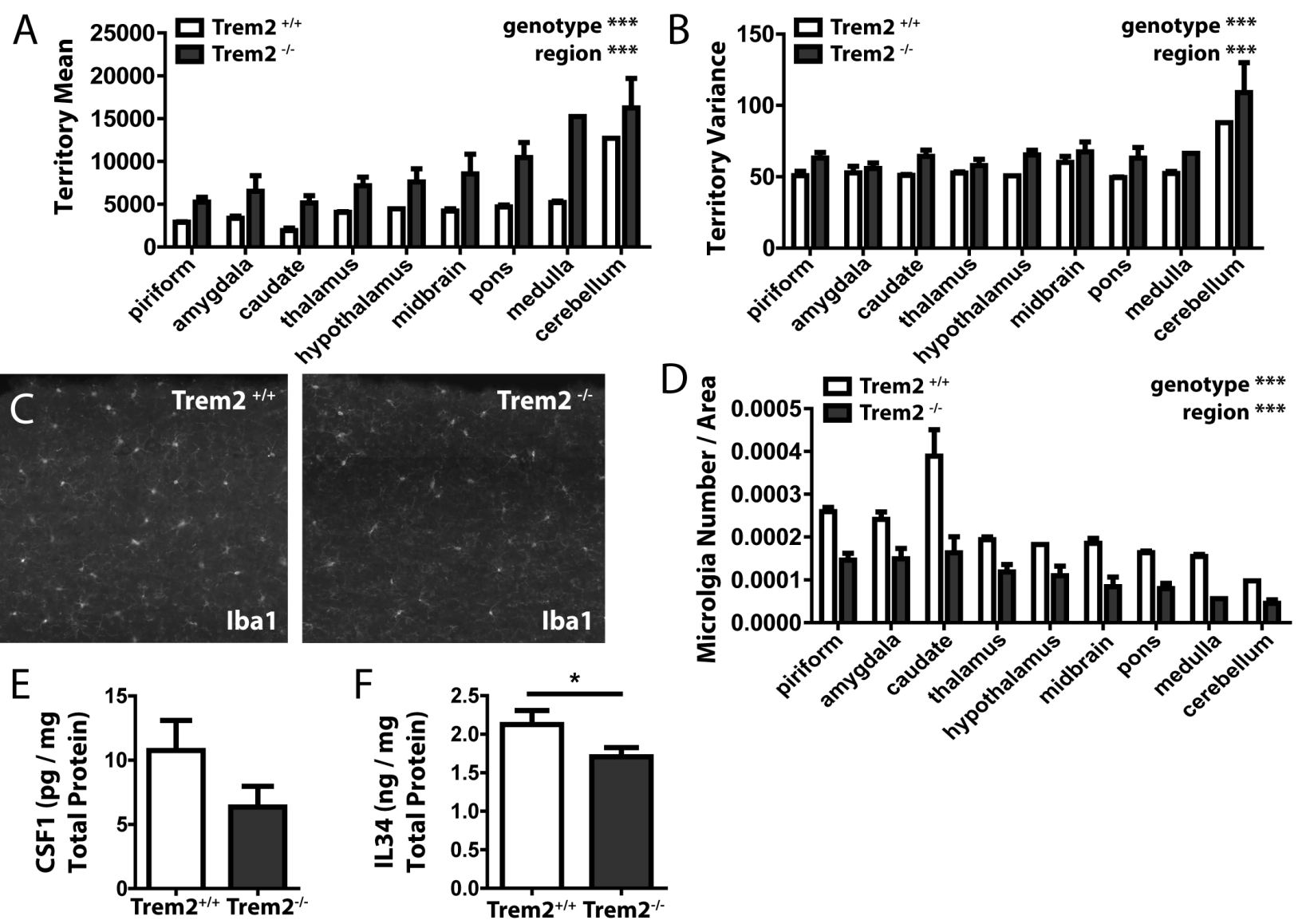

Figure S3. (A) Voronoi analysis was used to quantify the territory mean and (B) variance across brain

regions outside of the cortex and hippocampus. (C) Microglial number was quantified from slide scans of Iba1 immunohistochemistry on sagittal slices from Trem2 $2^{+/+}$and Trem $2^{-/}$mice (D) across the brain regions indicated. ELISAs were performed to assess protein levels of (E) CSF1 and (F) IL34 protein in Trem2 $^{+/+}$and Trem2 ${ }^{-/}$cortical lysates. Statistical results of 2-way ANOVAs are indicated, where significant, above graphs. ${ }^{*}(\mathrm{p}<0.05),{ }^{* *}(\mathrm{p}<0.001)$ 


\section{Figure 4}
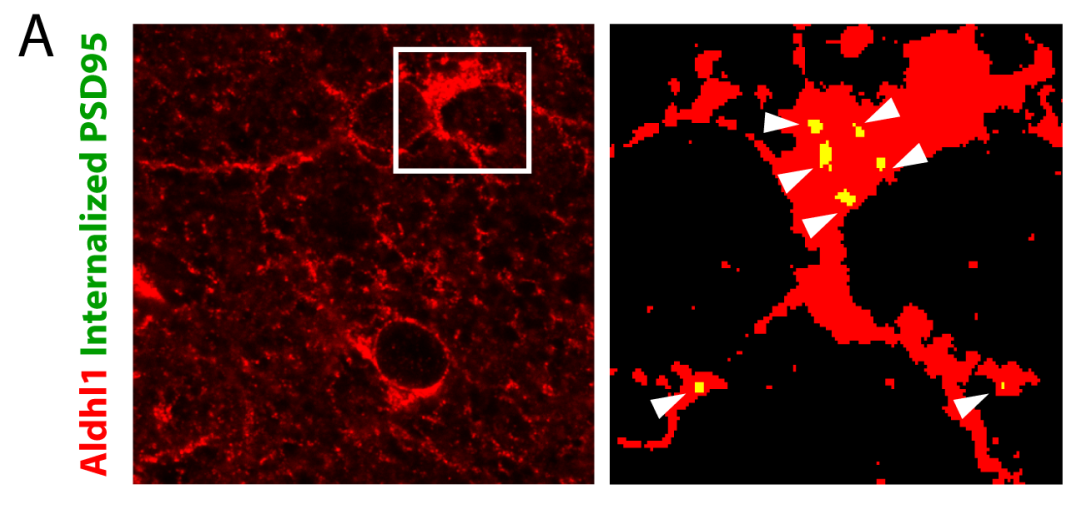

B
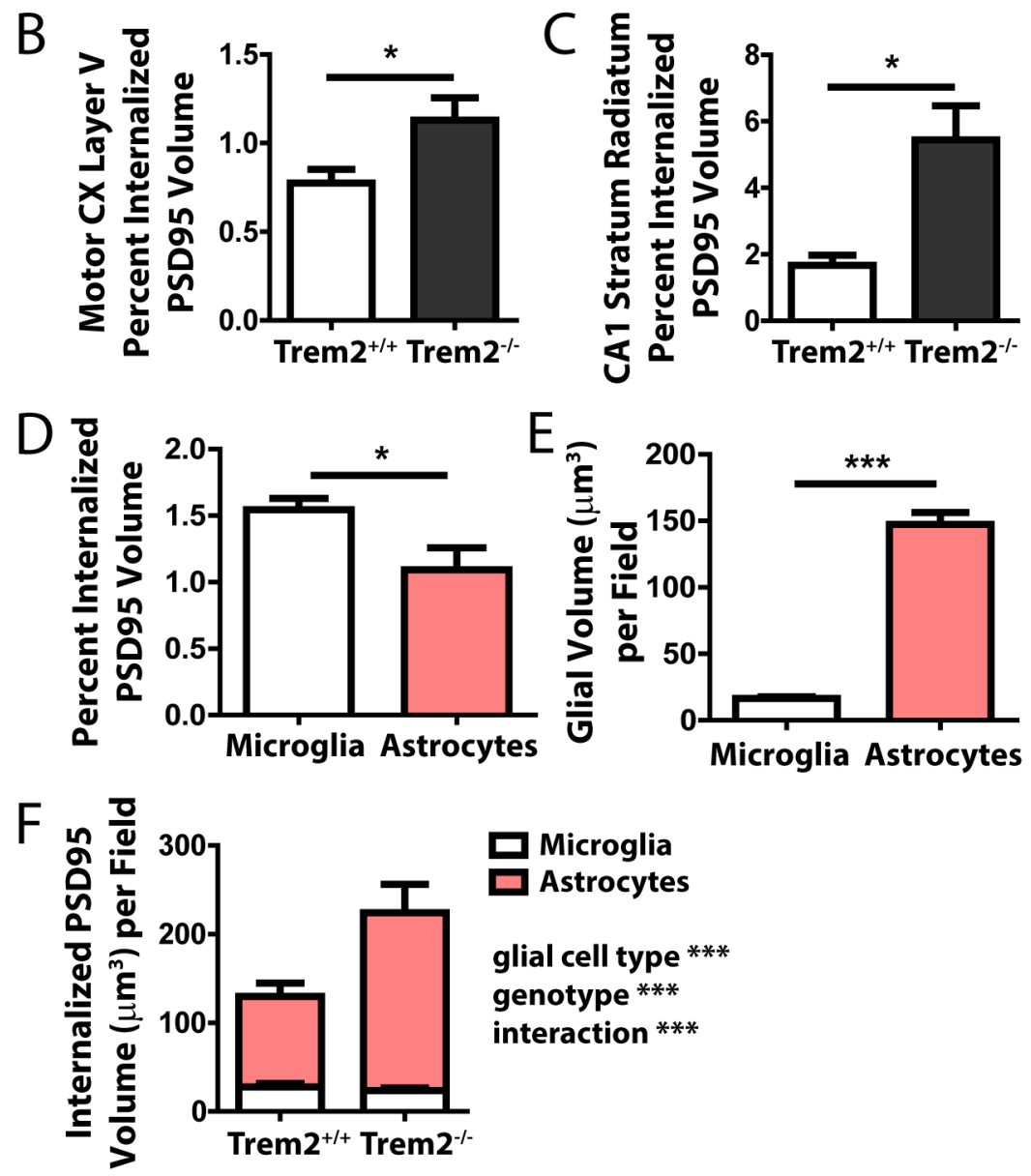

Figure 4. TREM2 deficiency increases astrocyte uptake of synapses. (A) Astrocytes were identified using immunohistochemistry for Aldhl1. Images were thresholded and quantification performed on binary images to assess PSD95 internalized within Aldhl1+ cells, indicated by white arrows. (B) There was a significant increase in the percent volume of astrocytes containing PSD95 in 1-month-old Trem2 $\%$ mice 
relative to controls in layer $\mathrm{V}$ of the motor cortex and (C) CA1 stratum radiatum. (D) The percent of Iba1 and Aldhl1+ cells that contained PSD95+ signal was quantified. (E) The volume of glia across the fields imaged for synaptic element quantification in motor cortex layer $V$ was compared. (F) The internalized PSD95 volume within each glial subtype was quantified per field. ${ }^{*}(p<0.05),{ }^{* * *}(p<0.001)$

\section{Supplemental Figure 4}

A

Astrocytes Internalized Synaptosomes
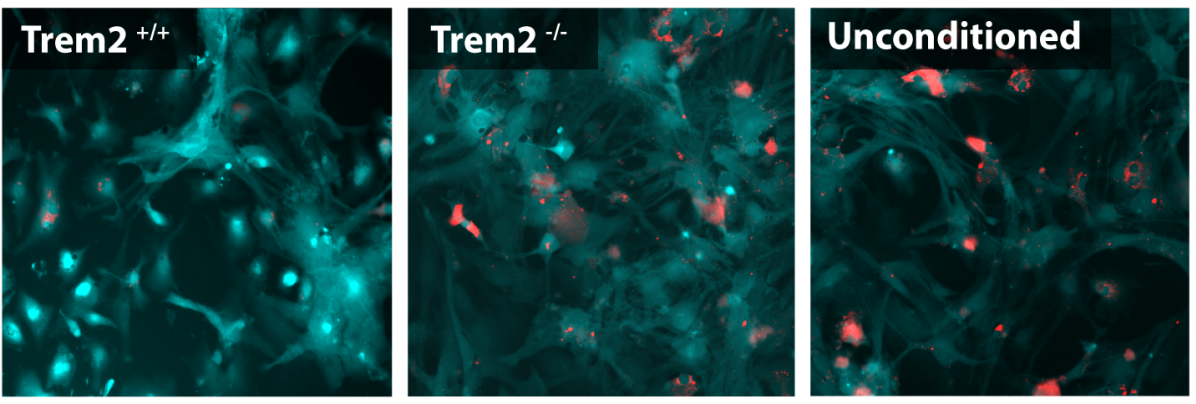

B
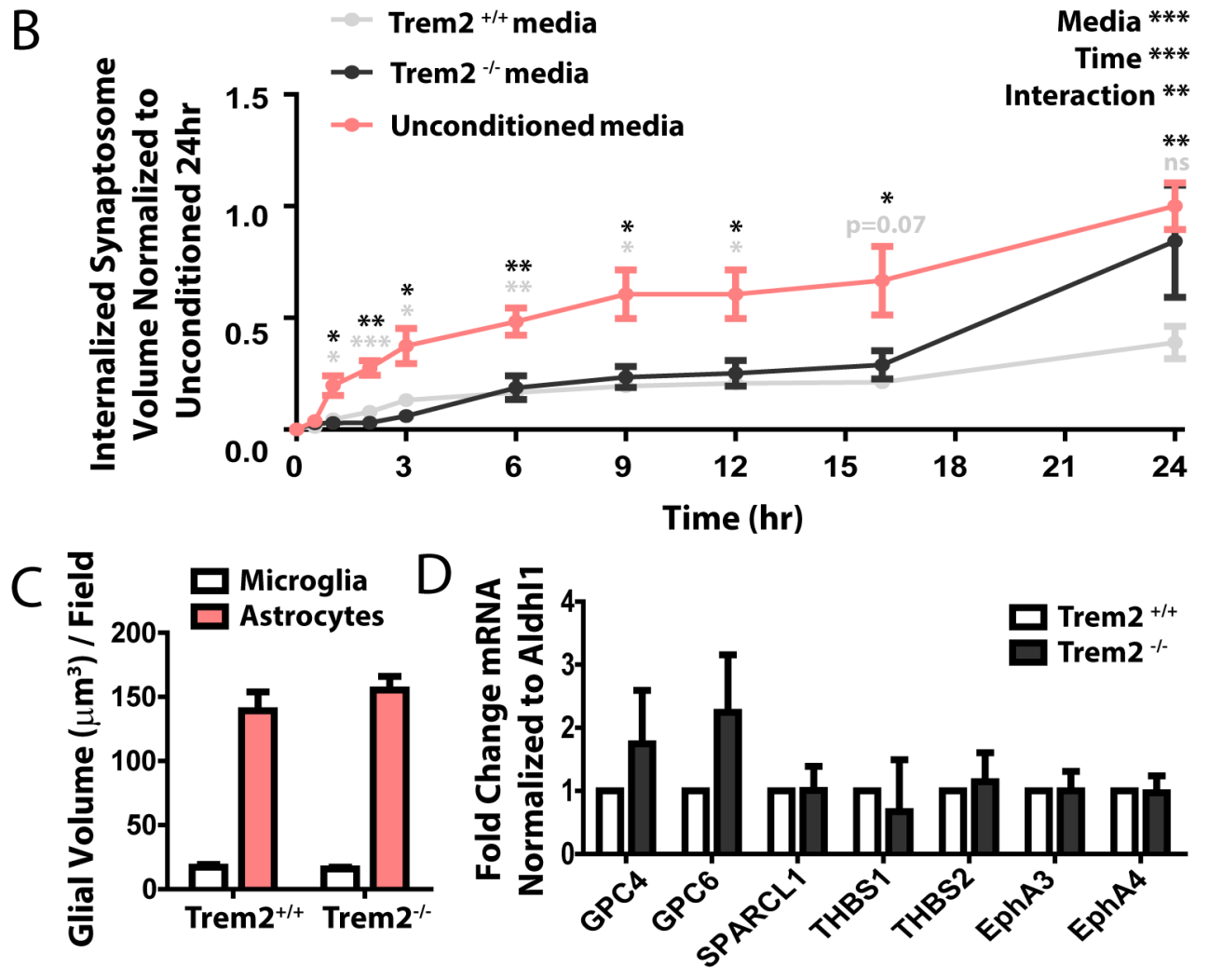

Figure S4. (A) Trem2 ${ }^{+/+}$astrocytes were cultured, labeled with CellTracker (cyan) and exposed to media 
from Trem2 $^{+/+}$or Trem2 ${ }^{-/}$microglia or unconditioned media for 6 hours. pHrodo conjugated synaptosomes (red) isolated from $\mathrm{Trem}^{+/+}$mice were added to the media at time 0 . Representative images were taken 24 hours after addition of synaptosomes. (B) Cells were imaged at the indicated time points and the percent of synaptosome volume within astrocytes was quantified and normalized to the percent volume of synaptosomes in astrocytes exposed to unconditioned media at 24 hours. (C) The total volume of microglia, labeled with Iba1, and astrocytes, labeled with Aldhl1, was quantified across each field. There was no significant difference in the volume occupied by astrocytes with Trem2 genotype. (D) qPCR was used to evaluate gene expression of astrocyte-derived factors that promote synaptogenesis and synaptic maturation in cortical lysates, which were normalized to gene expression of Aldhl1. Statistical results of 2-way ANOVAs are indicated above graphs. T-tests between Trem2 $^{+/+}$media and unconditioned media conditions are indicated above each time point in black and Trem $2^{-/}$media and unconditioned media conditions in gray. ${ }^{*}(p<0.05),{ }^{* *}(p<0.01), * * *(p<0.001)$, ns (not significant) 
Figure 5
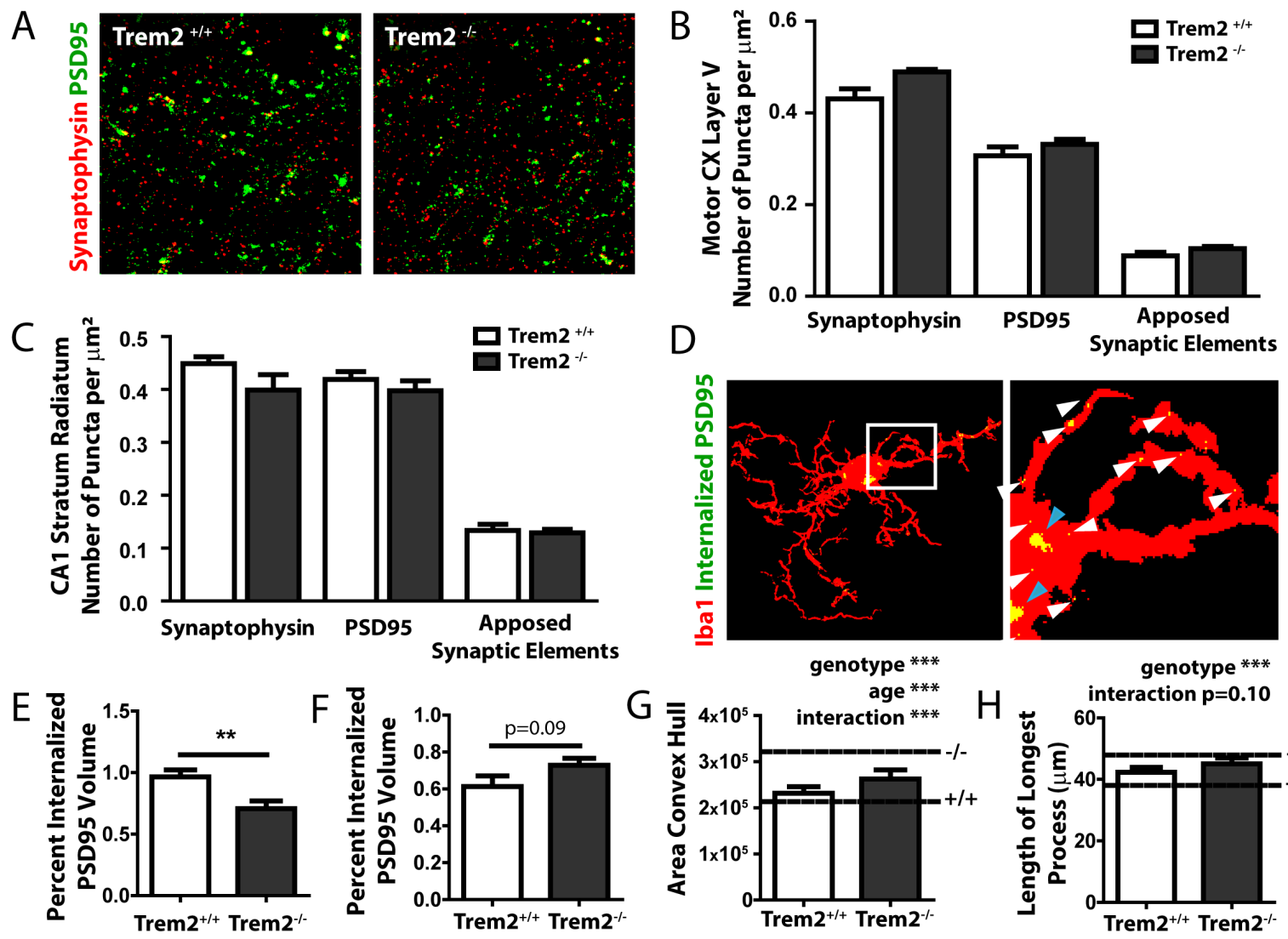

genotype ***

$G \quad$ age ${ }^{* * *} \quad-\quad$ interaction $p=0.10$
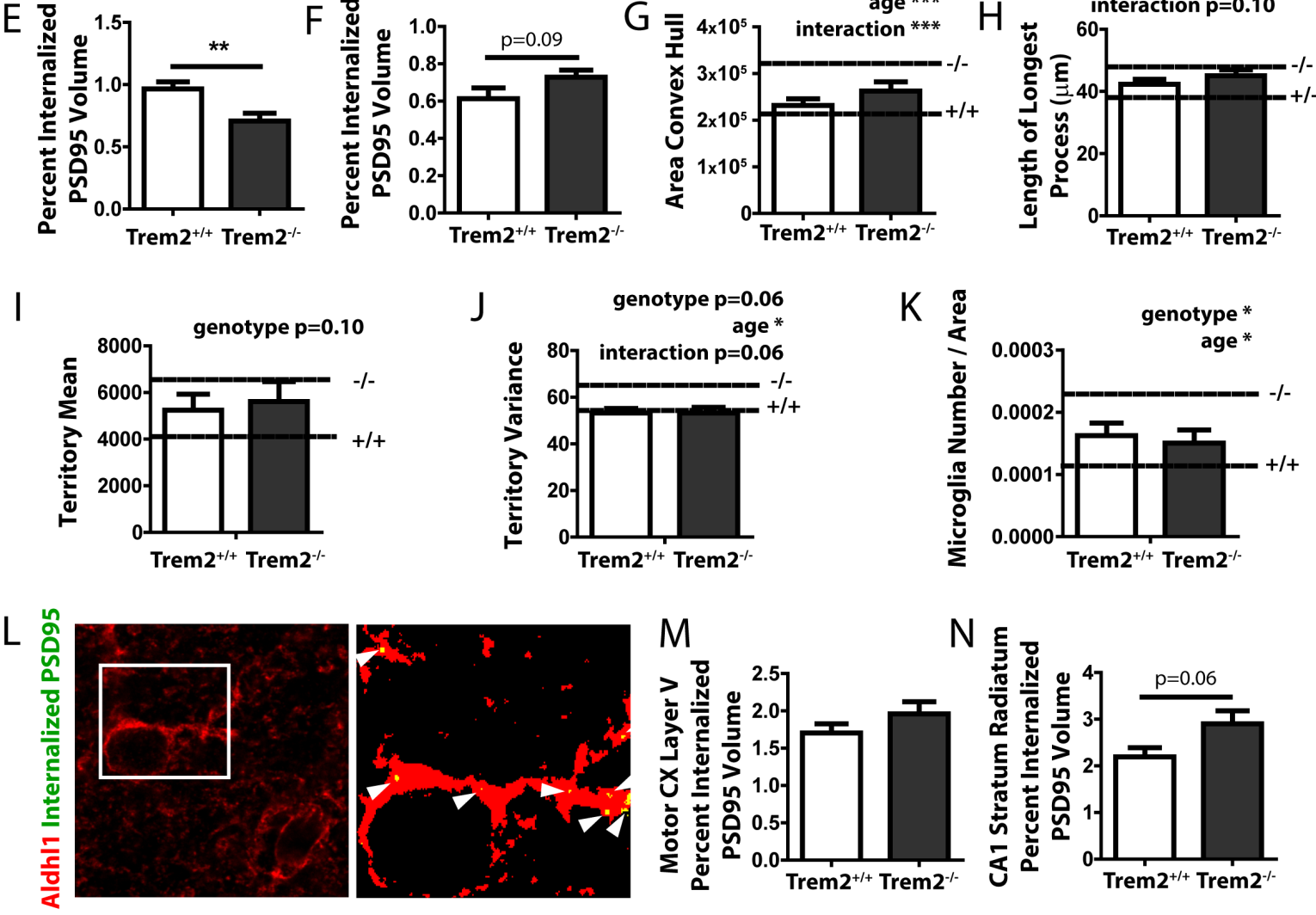
Figure 5. Effects of Trem2 genotype are largely normalized at 4 months of age. (A) Synapse number was assessed in 4-month-old $\mathrm{Trem}^{+/+}$and $\mathrm{Trem}^{-/}$mice using immunohistochemistry for synaptophysin (red) and PSD95 (green). (B) There was no significant effect of TREM2 deficiency on synapse number in layer $\mathrm{V}$ of the motor cortex or (C) in CA1 stratum radiatum. (D) The volume of microglia (Iba1, red) that contained PSD95+ elements (green) was assessed. White arrows indicate internalized PSD95 and blue arrows large PSD95+ inclusions $\left(>10 \mathrm{px}^{2}\right)$ which were quantified in $(\mathrm{E})$ layer $\mathrm{V}$ of the motor cortex and $(\mathrm{F})$ in CA1 stratum radiatum. In layer $\mathrm{V}$ of the motor cortex $(\mathrm{G})$ measures of microglial size were assessed by determining the average area of the convex hull using the hull and circle algorithm and $(\mathrm{H})$ by assessing the distance to the longest process using Sholl analysis. (I) Territory mean and (J) variance were quantified from Voronnoi tessellations and $(K)$ microglial density was determined. In $(G)-(K)$, the lines represent the values quantified in 1-month-old Trem2 $2^{+/+}$and Trem2 $2^{-/}$mice. In these analyses, 2-way ANOVAs were performed across age and genotype. (L) Synaptic engulfment in astrocytes was assessed by immunohistochemistry for Aldhl1 (red) and PSD95 internalized within these cells (green). (M) The percent of astrocyte volume containing PSD95+ elements was quantified in layer $\mathrm{V}$ of the motor cortex and $(\mathrm{N})$ in CA1 stratum radiatum. Statistical results of 2-way ANOVAs are indicated, where significant, above graphs. $*(p<0.05)$, $* *(p<0.01), * * * p<0.001)$ 


\section{Supplemental Figure 5}
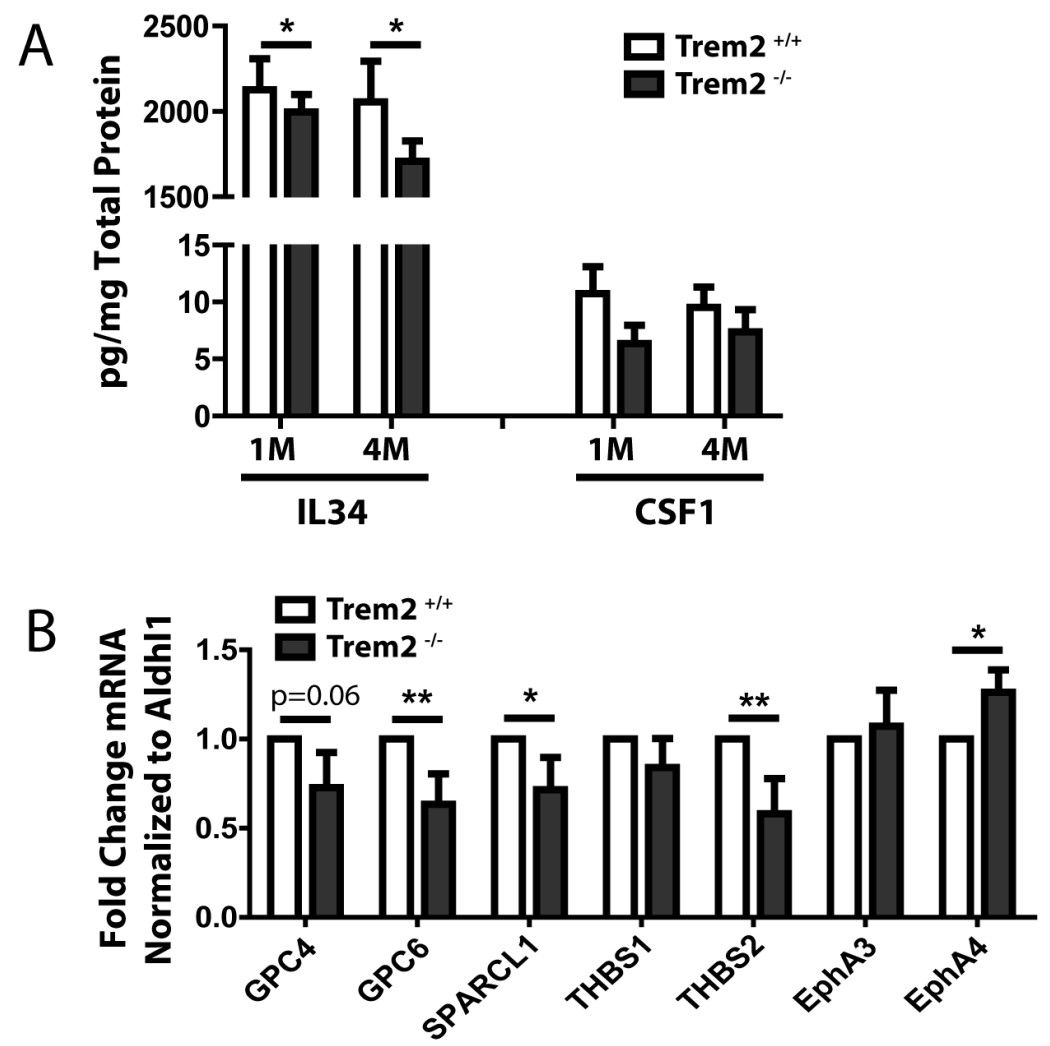

Figure S5. (A) ELISAs were used to quantify IL34 and CSF1 protein levels in Trem2 ${ }^{+/+}$and Trem $^{-/}$cortical lysates at 1 and 4 months of age. (B) qPCR was used to measure gene expression levels of astrocytic genes involved in synapse formation and maturation relative to gene expression of Aldhl1 in cortical lysates from 4-month-old Trem2 ${ }^{+/+}$and Trem2\% mice. * $(p<0.05),{ }^{* *}(p<0.01)$ 
Figure 6
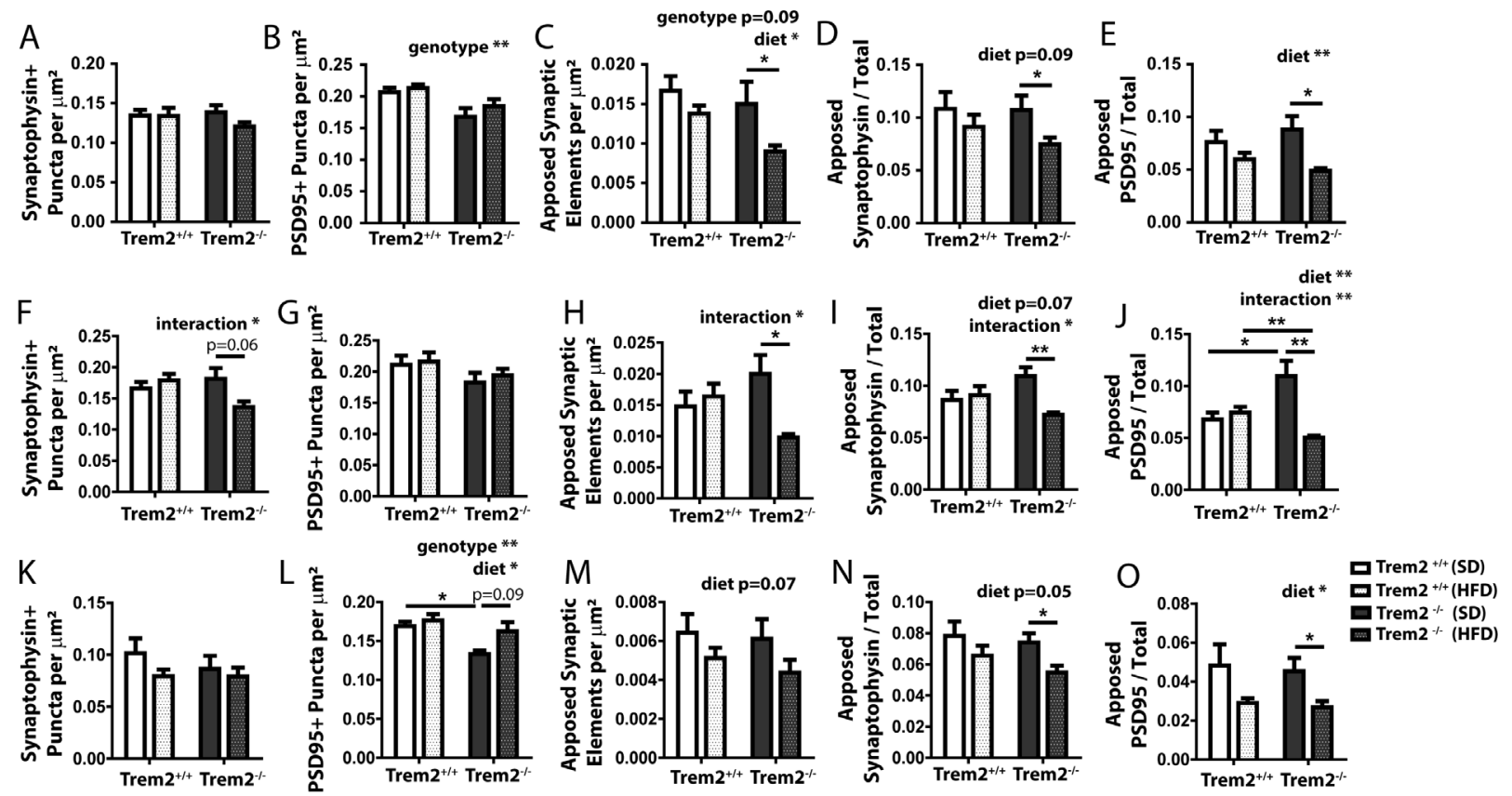

Figure 6. TREM2 deficiency alters synapse number in 4-month-old mice fed a high fat diet. Trem2 $2^{+/+}$and

Trem $^{-/}$mice were fed a standard diet until 1 month of age and then were either maintained on a standard diet (SD) or administered a high fat diet (HFD) until sacrifice at 4 months of age. (A) In layer $V$ of the motor cortex, synaptophysin+ element number, (B) PSD95+ element number and (C) apposed synaptic elements were quantified. (D) The percent of synaptophysin+ puncta that were within $0.5 \mu \mathrm{m}$ of PSD95+ puncta and (E) the percent of PSD95+ elements within $0.5 \mu \mathrm{m}$ of synaptophysin+ puncta were also assessed. In layers II and III of motor cortex, (F) the number of synaptophysin+ puncta, (G) the number of PSD95+ puncta, $(\mathrm{H})$ apposed synaptic elements, $(\mathrm{I})$ the percent of synaptophysin+ puncta within $0.5 \mu \mathrm{m}$ of PSD95+ puncta and $(J)$ the percent of PSD95+ elements within $0.5 \mu \mathrm{m}$ of synaptophysin+ puncta were quantified. Similar analyses were performed In CA1 stratum radiatum, quantifying (K) the number of synaptophysin+ puncta, (L) the number of PSD95+ puncta, (M) apposed synaptic elements, $(N)$ the percent of synaptophysin+ puncta within $0.5 \mu \mathrm{m}$ of PSD95+ puncta and $(0)$ the percent of PSD95+ elements within $0.5 \mu \mathrm{m}$ of synaptophysin+ puncta. Statistical results of 2-way ANOVAs are indicated, where significant, above graphs. ns (not significantly different), * $(p<0.05),{ }^{* *}(p<0.01), * * *(p<0.001)$ 